Article

\title{
Modeling Incipient Use of Neolithic Cultigens by Taiwanese Foragers: Perspectives from Niche Variation Theory, the Prey Choice Model, and the Ideal Free Distribution
}

\author{
Pei-Lin Yu \\ Department of Anthropology, Boise State University, 1910 University Dr., Boise, ID 83725, USA; \\ pei-linyu@boisestate.edu
}

Received: 3 June 2020; Accepted: 14 August 2020; Published: 7 September 2020

\begin{abstract}
The earliest evidence for agriculture in Taiwan dates to about 6000 years BP and indicates that farmer-gardeners from Southeast China migrated across the Taiwan Strait. However, little is known about the adaptive interactions between Taiwanese foragers and Neolithic Chinese farmers during the transition. This paper considers theoretical expectations from human behavioral ecology based models and macroecological patterning from Binford's hunter-gatherer database to scope the range of responses of native populations to invasive dispersal. Niche variation theory and invasion theory predict that the foraging niche breadths will narrow for native populations and morphologically similar dispersing populations. The encounter contingent prey choice model indicates that groups under resource depression from depleted high-ranked resources will increasingly take low-ranked resources upon encounter. The ideal free distribution with Allee effects categorizes settlement into highly ranked habitats selected on the basis of encounter rates with preferred prey, with niche construction potentially contributing to an upswing in some highly ranked prey species. In coastal plain habitats preferred by farming immigrants, interactions and competition either reduced encounter rates with high ranked prey or were offset by benefits to habitat from the creation of a mosaic of succession ecozones by cultivation. Aquatic-focused foragers were eventually constrained to broaden subsistence by increasing the harvest of low ranked resources, then mobility-compatible Neolithic cultigens were added as a niche-broadening tactic. In locations less suitable for farming, fishing and hunting continued as primary foraging tactics for centuries after Neolithic arrivals. The paper concludes with a set of evidence-based archaeological expectations derived from these models.
\end{abstract}

Keywords: Paleolithic Taiwan; aquatic-focused foraging; Neolithic Taiwan; agricultural adoption; niche variation theory; invasion theory; prey choice model

\section{Introduction}

"... these vast and largely uncharted [transitional] regions are not just uninhabited territory crossed on the way to an anticipated agricultural destination by evolutionary interstates without exits. They are, to the contrary, regions occupied by diverse, vibrant, and successful human societies that have developed stable, long-term economic solutions that combine low-level reliance on domesticates with continued use and management of wild species" [1].

Research into the encounters, interactions, and knowledge transfer between hunting and gathering peoples and agriculturalists began with collection of field data in the 1960s and 70s. Hunting and gathering societies were observed using a range of interaction strategies from unilinear agricultural adoption to sustained symbiosis founded on forest product exchange [2]. Interaction studies continued 
with cultural history investigations and pattern recognition in the 1980s and 90s, and moved toward the synthesis of the ways that variability in relationships can lead to greater understanding of human social change [2,3]. This observed variability is germane to understanding evolutionary relationships, and framing archaeological expectations for major transitions such as the Neolithic.

The topic of agricultural adoptions by island hunter-gatherers offers perspectives on Neolithic onsets, particularly regarding the influences of aquatic resources, immigration, demographic pressure, constraints on mobility, and migrations [4,5]. Taiwan's biogeographic position at the east-west nexus between Southeast China and the islands of the Pacific Ocean and the north-south nexus of the Japanese archipelago and SE Asia places it at the intersection of diverse climates and ecosystems and the center of a cultural and adaptive interaction sphere rooted in the Paleolithic. As such, the island is an important case study with relevance for the Neolithicization of coastal and island Southeast Asia and eventual Austronesian expansions across Oceania [6-13]. The Neolithic onset of Taiwan is notable for its late date of circa (c.) $6000 \mathrm{BP}$ compared to mainland China [10-14]. Neolithic cultures proceeded to expand, become regionally differentiated, and complex at a rapid rate: by $4500 \mathrm{BP}$, agriculture-based societies had radiated to most of the island, growing millet, rice, tubers, and tree crops; Middle Neolithic settlements are marked by social ranking, megaliths, production of prestige goods, and sizeable structures and features [15-17].

The nature of the initial interaction with Paleolithic groups, which established the foundations for the decline of foraging and replacement by agriculture, is not yet well understood, although most Taiwanese researchers agree that Neolithic cultures are not directly descended from Upper Paleolithic peoples [16]. Where might we find reference information about the adaptive responses of native Paleolithic foraging peoples to invasive dispersals of Neolithic immigrants? A promising area is the evolutionary study of various non-human species in order to better understand the process and its outcomes. With specific reference to subsistence changes associated with invasive dispersals, behavioral ecologists have investigated and described important parameters that influence the decision making of migrating individuals as well as the attendant costs and benefits to dispersers $[18,19]$. The adaptive response of native populations-who are 'dispersed upon'—is less well studied, but of particular evolutionary interest in the case of Neolithic transitions. The decision-making process for groups facing unfamiliar crop foods and cultivation techniques, their assessment of opportunity costs to mobility needed for food, technological materials, social networks, and other resources [2,20-22], and the ensuing societal and environmental feedback loops make up the localized and evolutionarily significant initial conditions of food producing societies.

In order to derive a working hypothesis about the adoption of agricultural practices by Paleolithic hunter-gatherers experiencing invasive migrations, this paper describes Taiwan's unique geographic position and biodiversity, summarizes current environmental and archaeological knowledge about the transitional Paleolithic to Neolithic transitional period, models Late Paleolithic foraging niche breadth using Lewis Binford's database of hunting and gathering peoples, and assesses the implications of niche variation theory, the prey choice model, and the ideal free distribution for mutually influential adaptive responses of Paleolithic Taiwanese foragers and arriving Neolithic Chinese farmer-fishers. Predicting variations in this process has important implications for settlement, the adoption of cultivation, and social integration by native foragers. The paper concludes with proposed lines of evidence for hypothesis testing with the archaeological record.

A note on spelling: for Chinese words, the Pinyin system of romanization is used except in the case where the Wade-Giles system is used for longstanding and familiar names. For Taiwanese indigenous words, Romanized versions that are commonly accepted in the scholarly literature are used. For site dates, BP or BC are used as presented in cited sources.

\section{Human Behavioral Ecology and Subsistence Strategies of Invasive Dispersals}

Human behavioral ecology (HBE) has developed an array of intellectual tools to explore the dynamic relationships between organisms and the environment using an evolutionary 
framework [23-28]. In comparison and complementary with macroecological models that explore broad patterns in extant data, concept models are derived from the principals of natural selection and general theory of behavior. These models seek to link behavior to expected material outcomes [28]. The development of testable hypotheses regarding the cumulative effects of decisions and broader patterns of evolutionary change aspire to bridge these two scales of analysis [26,29].

From early studies in optimal foraging, HBE is now exploring the socioecological contexts influencing why individuals modify their environments, move to new places, begin to produce food, and enter into cooperative or coercive social relations [26]. The ideal free distribution and its corollary, the ideal despotic variant [30] provide an explanatory framework to predict when individuals will disperse or migrate to a new habitat, based on density-dependent changes in the suitability of the habitats available to them [31]. This model ranks habitats by their quality, assessed by the fitness of the occupants. The Ideal Free Distribution (IFD) assumes that a dispersing organism will decide to settle in the preferred option of several habitats that differ in suitability (e.g., availability of resources, exposure to hazards, and other characteristics). Desirable habitats are occupied chronologically in rank order, presuming no competition from others. The ideal despotic variant (IDV) highlights immigration and differential access to resources, in which groups seeking to settle in already-occupied highly ranked habitats are deterred from entry by defense and are thereby forced to settle in lower-ranked locations. The habitat implications for this model can be provocative: the Allee effect [32] can result in positive feedback effects of population density in contrast to density dependent resource depression. Fruitful assessments of the Allee effect include North America and Australia, where certain prey types predicted by the Prey Choice Model (PCM) would be pursued on encounter and increase population size with increasing land use intensity [33-35]. The ideal free distribution has also been examined in island habitats, immigration, and settlement in Polynesia [31], California [36], and will be the focus of a future paper concerning Taiwan [37].

Returning to the impacts of dispersing farmers on foraging, the niche concept is foundational to both behavioral ecology and macroevolutionary approaches. Binford's [20] definition of niche is the dynamic articulation between the capabilities of a group of 'actors' and the organizational properties of their habitat: the types and quantities of resources as well as how, when, and why actors use them. A foraging niche is positioned along a continuum from specialized to generalized, in which generalized actors feed on a greater proportion of the species available in the habitat, and specialized actors feed on a smaller proportion $[20,38]$. Foraging niches are in a constant state of flux through adaptive responses to changes in prey or resource type, frequency, and distribution. Organizational properties of the habitat influence the distribution and frequency of prey. The process by which individual foragers take into account energetic costs and returns when encountering potential prey (including plants) is described in the encounter-contingent prey choice model (PCM) [39,40]. With a stipulated goal of maximizing net energy returns, the order of ranking for prey is determined by the evaluation of which items to take upon encounter [26,41-45]. The prey choice model predicts that, all other things being equal, high ranked resources will always be taken upon encounter, but lower ranked resources will only be taken if they will increase the overall return rate (expressed as energy/time). Under conditions of resource stress, the reduced encounter rate for highly ranked resources increases the likelihood that lower ranked resources will be taken. The implication is that scarcity of high ranked resources tends to encourage a broader dietary niche as energetic costs of the search eventually overwhelm the advantages of being selective.

During invasive dispersals of morphologically and functionally similar populations into occupied territories, the overlap between niches that results from similar prey choices increases competition, depresses prey, and in turn narrows the niche breadth of both dispersers and natives [46]. With regard to invasive immigrations, understanding the initial contexts and processes of competitive interactions provides an important benchmark for predicting the long-term consequences of invasion. Foraging niche breadth is one such factor: a broad or generalized foraging niche is considered to be key in determining the success of dispersers [46], but less is known about the effects upon pre-existing 
niche breadths of native species. Generalized native foraging niches would provide a wider range of prey options under competitive pressure; therefore identifying conditions for niche generalization versus specialization is helpful in characterizing niche breadth.

Niche variation theory describes the process of 'ecological release' by which foraging niche breadth broadens and diversifies when inter-species competition is reduced [18,47-50]. This mode of niche expansion increases foraging variation among individuals (or groups) rather than individual niche breadth. Subsequently, within-population variation is a key requirement for frequency-dependent interactions that may drive evolutionary diversification and influence the population dynamics and ecological interactions of species [18] (Figure 1).

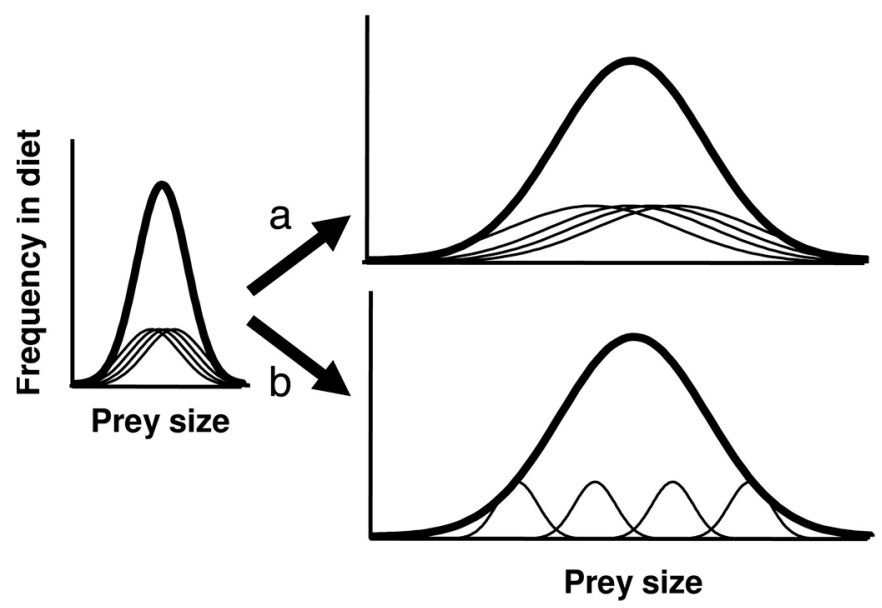

Figure 1. Two alternative patterns of population niche expansion. A population that uses a narrow range of prey sizes can increase its population niche breadth (bold lines) in two ways. (a) Inter-group niche breadths (thin lines) can expand, resulting in no increased niche variation among individuals. (b) Individual group niche breadths can remain limited, whereas groups diverge from each other to increase among-group variation (after [18], used by permission of lead author).

The obverse of ecological release-competitive pressure-is predicted by "classic invasion theory" (sensu [38]). A successful invading group may displace similar native species by overlapping their niche through direct competition for preferred prey. A generalist diet is a common trait of successful invaders, allowing them to exploit diverse resources in novel environments, competitively exclude native species, and breed successfully [51]. Under this theory, the decline of native species following an invasion may be a consequence of direct interspecific competition for prey e.g., [52,53]. If species occupy a larger niche in the absence of interspecific competition $[50,54]$ under conditions of competition, both dispersing and native species are expected to occupy smaller niches than their allopatric equivalents [55]. In a potential variant, increased competition for resources could necessitate an increase in dietary niche breadth in order to maintain energy requirements [56] (also see below). Empirical evidence for different taxa indicates that interspecific competition can cause the niche widths of consumers to increase or decrease, depending on the context [57], with generalists having more capacity to increase dietary niche breadth. Niche breadths of both dispersing and native competitors is an important contextual factor in determining invasion success and predicting the impacts of invaders on biodiversity and foraging niche (e.g., [46,58]). The human foraging niche is highly flexible and may expand, contract, or shift; under some circumstances, the diets of different groups may functionally be as disparate as separate species. All other things being equal, in the early phases of invasion, native populations with a broad dietary niche are expected to have more adaptive options when facing competition.

Behavioral ecology applications have largely focused on in situ domestication or local adoptions of plant foods by landlocked human groups including intensified use of wild species and the domestication process for early cultigens [3,41-45,59]. Gremillion and Piperno [42] employed the prey choice concept to predict the manipulation of low-ranked plants that eventually became fully domesticated seed 
crops. In the case of invasive competition, the prey choice model predicts that dispersing competitors' appropriation of a higher proportion of available resources would incentivize natives to consider including unfamiliar, and (at least initially) low-ranked prey in the diet. Of course, there are limits to the expansion of niche by incorporating lower ranked prey items; eventually low ranked options are exhausted. The niche construction theory [59,60] employs Elton's [38] concept of an organism or population that modifies habitats to enhance energetic rates of return. With regard to plant domestication, there is room for debate regarding the onset of niche construction as a maximizing strategy during times of resource abundance (sensu $[60,61])$ or a Malthusian response to resource depression [59]. The latter approach is germane to resource depressions such as those we expect to follow invasive dispersals. A niche construction tactic like agriculture could initially offset direct competition for forager resources by providing an additional food source, but as foraging complements most traditional farming diets, it is expected that highly preferred wild resources would become depleted within a certain radius of sedentized farming communities. Therefore, a correlation to the working hypothesis for the Taiwanese Neolithic is that niche construction practices of immigrating farmers reduced mobility and limited foraging to the surrounding area. Preferred wild prey would rapidly become depleted in these areas, reducing encounter rates for native foragers. The harvest of lower ranked prey would broaden the subsistence niche for both the forager and farmer in these locations, and when the limits of low ranked prey are reached, foragers would be faced with two alternatives: adopt agricultural practices or migrate. This process is predicted for areas where farmers settled initially in direct overlap with forager territories.

A hypothesis may now be developed for the Neolithic transition of Taiwan: If the assumptions of PCM hold, with increasing land use intensification, high ranked wild prey should rapidly become depleted in areas of high suitability, reducing encounter rates for native foragers. The harvest of lower ranked prey should broaden the subsistence niche for both foragers and farmers in these locations, and when the limits of low ranked prey are reached, foragers would be faced with two alternatives: adopt agricultural practices or migrate. This process is predicted for areas where farmers directly overlapped with forager territories.

If assumptions of an IFD with Allee effects hold, we expect to see an initial increase in habitat suitability associated with habitat modification resulting from farming and/or intensified foraging, and associated increases in encounter rates for certain prey types that do better with heterogeneous vegetation and successional communities. In this modified expectation of niche variation theory, ecological release and niche variation resulted not from decreased population densities and resource demand, but manipulation of habitat characteristics that increase encounter rates.

The utility of model-based approaches for formulating explanations about evolutionary transitions of human subsistence is mediated by the scientists' ability to make testable inferences about the foraging niches of individuals and societies that we cannot observe directly. The archaeological remains of past dietary behaviors serve as the basis—albeit imperfectly preserved—for inferences regarding prey choice and variations in niche breadth (Figure 2; see also [26]).

Assembling reference knowledge about processes that are germane to, but independent of, past phenomena of interest can complement limited evidentiary data to help guide archaeological research questions $[20,29,62-64]$. Behavioral ecology concept models can be informative about the dynamics at the level of the individual, and assist in the development of hypotheses about systems that can be assessed with archaeological data. The case of the Taiwan Neolithic offers an opportunity to examine reference information about foraging niches from a mountainous island habitat. 


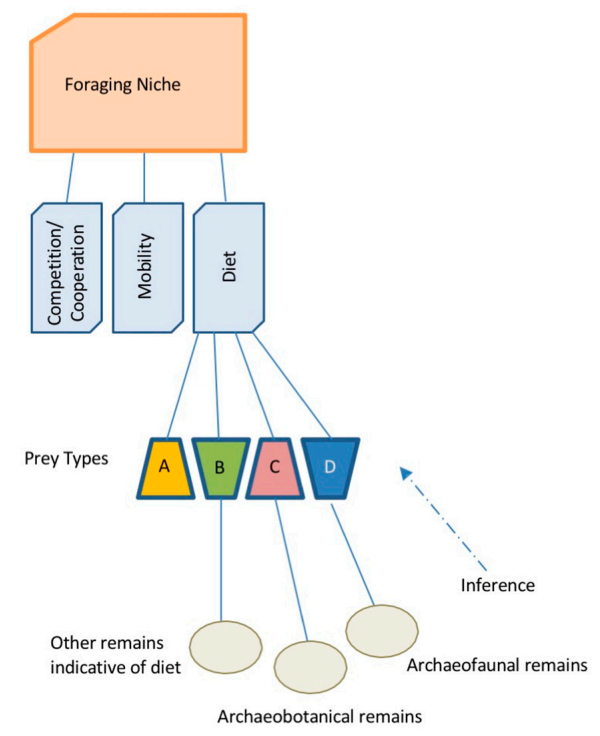

Figure 2. Relationship of niche to diet, prey types, and archaeological inference.

\section{Materials and Methods}

To scope a test for the effectiveness of the prey choice model versus the ideal free distribution with Allee effects, the paper first modeled Paleolithic foraging to create a ranking of wild prey types preferred by foragers. This is followed by a summary of the salient characteristics of Taiwan's first farmers to estimate the influence of farming combined with prey choice on habitat preferences.

\subsection{Modelling Taiwan's Paleolithic Niche Breadth: Paleoenvironment and Subsistence}

The unique geographic position, climate, and landforms of Taiwan have had a profound influence on ecosystem characteristics and contexts since the Last Glacial Maximum. The island lies at the intersection of multiple climatic zones and ecosystems, conditioning for highly diverse habitats and access by boat from the west, north, and south. Along the eastern margin of the Asian continental shelf and the western edge of the Pacific Ocean and between longitude $120^{\circ} \mathrm{E}$ and $122^{\circ} \mathrm{E}$ and latitude $21^{\circ} \mathrm{N}$ and $25^{\circ} \mathrm{N}$, Taiwan's geographic area is about $36,000 \mathrm{~km}^{2}$, with a north-south distance of c. $394 \mathrm{~km}$ and east-west distance of about $140 \mathrm{~km}$. Okinawa lies to the north, China lies c. $130 \mathrm{~km}$ to the west, Luzon Island about $250 \mathrm{~km}$ to the south, and the Pacific ocean to the east. Dozens of surrounding islands include the Penghu (Pescadores) group, Ludao (Green Island), and Lanyu (Orchid Island). The coastline is about $1566 \mathrm{~km}$ around the perimeter, and together with 129 sizeable rivers and more than 100 wetlands and estuaries, provides abundant aquatic habitats. Taiwan's western coastal plain is crossed by large meandering rivers, grading upward through dense deciduous forest in mountain footslopes to sub-tropical cypress and other evergreens at mid altitudes to an alpine oak scrub and steppe. Before urban development, estuaries and extensive low gradient wetlands lined the northern and western coasts, with a large lake basin where the Taipei metropolis now sits. On the east coast, most piedmonts are narrowly constricted and limited flat areas are mostly alluvial outflow deposits from steep mountain rivers.

Taiwan's landmass is more than $80 \%$ mountainous with tectonic activity manifested by volcanism, earthquakes, and frequent landslides. These steep mountains create diverse microhabitats and influence the mobility and foraging patterns of game species. The central mountain range forms the spine of the island, with more than 100 peaks higher than $3000 \mathrm{~m}$ above sea level, although the island is only c. $144 \mathrm{~km}$ at its widest point. The smaller coastal mountain range to the east is about $140 \mathrm{~km}$ long with peaks of about $1000-1500 \mathrm{~m}$. A long, narrow inland valley runs north-south between the central and coastal mountain ranges, and three major lake basins are located in the north, west, and west-center (as Figure 3). 


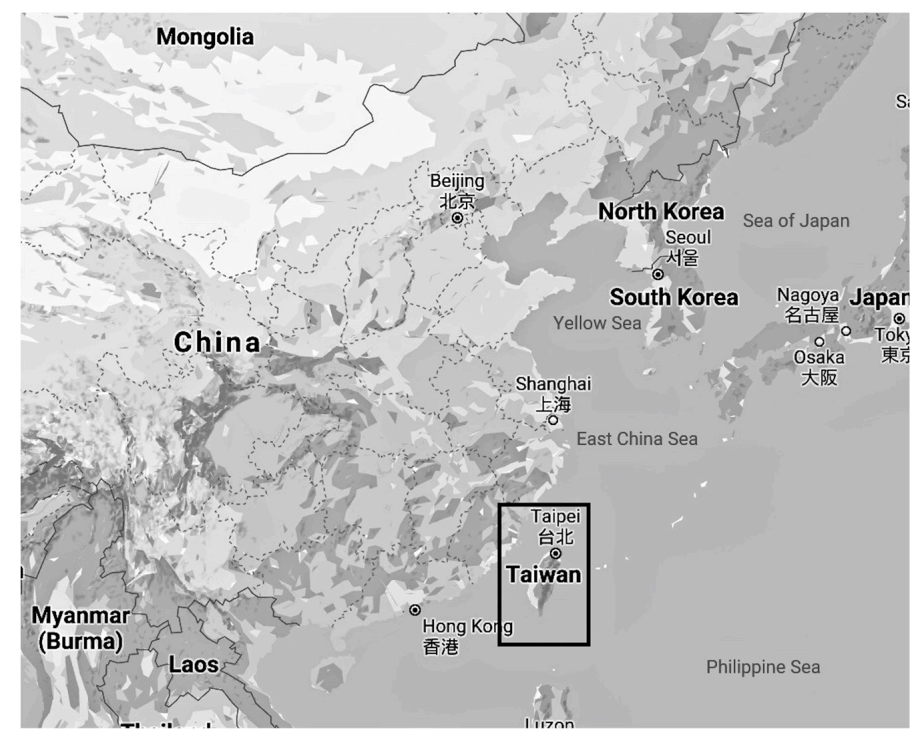

Figure 3. Location map of Taiwan.

Currently, the Tropic of Cancer runs through Taiwan, creating a sub-tropical climate merging into tropical conditions in the south. Sea breezes, typhoons, and monsoons keep modern temperatures warm, with annual averages between 21.5 and 24.5 Centigrade. Annual humidity is high with average rainfall between 1820 and $2720 \mathrm{~mm}$. High seasonal variability in rainfall comes from the rainshadow effect and seasonal variation in wind direction; the central west coast is driest and the northeast coast, the wettest.

The wild vegetation of Taiwan is adapted to the temperature and moisture gradient [65], and the two main forest ecoregions currently include subtropical evergreen forests across most of the island and tropical monsoon rainforests on the southern tip. Temperate and sub-alpine communities exist in high mountain settings. During the middle Holocene optimum, pollen records indicate that during the time period around $6100 \mathrm{BP}$, warm climates allowed tropical evergreen forests to grow across most of the island [66]. Overall, climates have undergone major fluctuations in the past 12,000 years, and during the Tainan Paleoenvironmental Period (early to middle Holocene, 10-5 kyr BP), temperatures were warmer overall. A variety of geological indicators show that melting glaciers and local tectonics led to a rise in regional sea levels, reaching a maximum at around $6500 \mathrm{BP}$ [67] and inundating the margins of Taiwan's western coastal plain, the Penghu Islands and others [68], and the Southeast Chinese coast across the strait [69]. Environmental fluctuations during the subsequent Nankuanli Geological Period (c. 5000-3000 BP) included actively fluctuating sea levels [67,70]. Marine transgressions and retreats created a dynamic estuarine and littoral environment, particularly in the low relief western and southern plains of Taiwan and the SE China coast. Chen et al. [68] noted localized major marine transgressions at c. $4700 \mathrm{BP}$, and at the same time, uplifts in the southwest central mountains caused aggradation and drainage formation and movements. Estuarine and marshland resources were abundant, albeit shifting, during this period of environmental upheaval on both sides of the Taiwan Strait.

These warmer climates likely created wind patterns, rainfall, seasonal variance, and ecosystems that are different from today's. Rising sea levels would have altered land availability, and vegetation communities would have resembled those currently on the southern tip of the island. However, ecosystems likely varied according to elevation, slope, and aspect, much like today.

Largely isolated from mainland influences since the late Pleistocene, Taiwan's highly diverse flora and fauna include unique island forms such as the Taiwanese cypress (Taiwania cryptomerioides), bay tree (Machilus kusanoi), Formosan bear (Ursus thibetanus formosanus), clouded leopard (Neofelis nebulosa brachyura), boar (Sus scrofa taivanus), Sika deer (Cervus nippon taioanensis), sambar (Rusa unicolor swinhoei), serow (Capricornis swinhoei), muntjac (Muntiacus reevesi), pangolin (Manis pentadactyla pentadactyla), rock macaque (Macaca cyclopis), and giant flying squirrel (Petaurista alborufus). Many large bodied 
species now limited to forested upland reserved areas were broadly distributed in the piedmont and forested interface with the coastal plain [71]. The island is home to a wide variety of endemic and migratory birds, and the marine fishery includes diverse and abundant shellfish, crab, and shallow water fish populations on the west and south coasts. A productive pelagic fishery lies off the east coast, and edible kelp and algae are common. The pre-20th century freshwater fishery was also diverse including shellfish, crayfish, and catadromous (sea-spawning migratory) and landlocked species including Formosan salmon (Oncorhynchus masou formosanus).

\subsection{Paleolithic Environment and Cultural Adaptations}

Archaeological preservation of the Paleolithic to Neolithic transitional period is complicated by marine transgressions, mountain building, and sediment aggradation during the significant period between 14,000 and 6000 BP [5,67]. Currently, Taiwan's earlier Paleolithic cultural sites, termed Changbinian, have been found primarily in caves along the rugged east coast and date to c. 20,000-6000 BP [72-77]. The type site of Baxiandong (Pah-Hsien-Tung) is made up of a beach caves located in rugged terrain that was somewhat inland during the early period of occupation (Figure 4). The lithic assemblage of Baxiandong lower levels includes unifacially flaked choppers and cobble flake tools (c. 20,000-25,000 BP) [75] made of sandstone pebbles sourced from nearby beaches [77] that were knapped on-site based on refit data [72]. Changbin core/flake pebble technological systems show affinities with the Paleolithic cultures of the Ryuku Islands and the Philippines [77]. Faunal remains mostly represent fish, shellfish, and cervids [75,77].

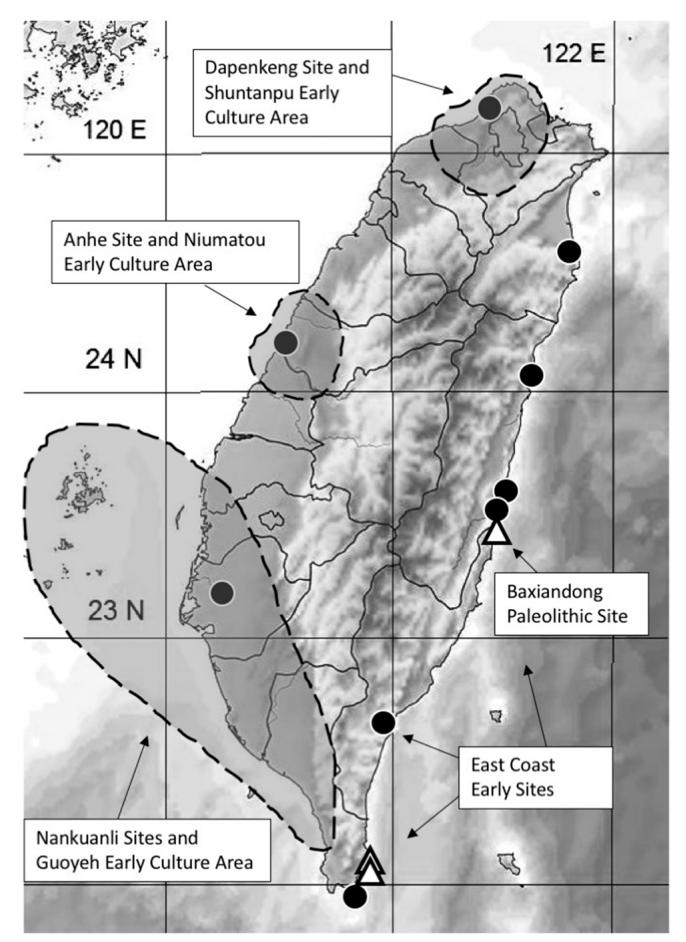

Figure 4. Map of Taiwan's Paleolithic and early Neolithic culture areas and sites (Adapted from [78]).

From Changbinian origins, regional foraging variants emerged at about 15,000-5000 BP. These cultures are termed as the Persistent Upper Paleolithic because they retain Paleolithic technological systems and lack ceramics [79]. The upper Paleolithic levels of Baxiandong include mostly unretouched flakes, but some pieces show evidence of faceted striking platforms. Tool types include side scrapers, points, knives, and notched scrapers made of higher quality raw material such as quartzite and chert [72]. Hearth-like ash lenses have also been found [72,77]. Other Persistent Upper Paleolithic sites are located in the northwest near Taipei $[73,74,80]$ including the northwest Wangxing culture, which terminates at c. $6000 \mathrm{BP}$ and is described as an adaptation particular to this region $[81,82]$. 
Persistent Upper Paleolithic sites are also found the central west near Miaoli and Taichung [80-83], in the southwest near Tainan [74], on the southern tip at O-luan-pi, Xiaoma, and Longkeng [84], the southeast near Pingtung [85,86] and southeast near Taitung [87]. In particular, the time period of $6500-5000 \mathrm{BP}$ is well-represented in the south. Organic preservation is rare at most Paleolithic sites, mostly consisting of fragmented animal and fish bone as well as shell [ibid], which suggests a mixed subsistence strategy. The presence of horn implements and needles from large body size game at Baxiandong indicates that deer and other large prey were taken regularly [75-77]. Overall, archaeological evidence indicates that Taiwan's Paleolithic cultures were evolutionarily dynamic and adapted to diverse habitats, with some emphasis on aquatic resources. From Asian cobble technologies after the Pleistocene to Holocene transition, Persistent Upper Paleolithic cultures shifted to smaller lithics of higher quality raw materials, retouch techniques, and an increase in bone tools as well as regional variation in subsistence, technology, and settlement.

\subsection{Reference Information about Foraging from the Binford Hunter-Gatherer Database}

Lewis R. Binford's database of hunting and gathering peoples $[20,88]$ includes environmental data for climate, topography, soils, and primary (plant) and secondary (animal) biomass from individual weather stations around the globe. Johnson [29] demonstrates that habitat data can be used to project hunter-gatherer subsistence, social organization, and demography where foraging societies no longer reside, based on regressions of variables of climate data and living hunter-gatherer societies. The Binford database is used to calculate projections for foraging behaviors based on a global sample of data from 339 ethnographically documented hunting and gathering societies that is geo-referenced to climatic and environmental parameters. This allows for informed estimates of foraging behaviors where detailed ethnographic information is not available such as Taiwan. The projection for Taiwan's anticipated foraging niche breadth is based on modeled foraging subsistence diversity and climate and environmental data from 27 Taiwanese weather stations (Figure 5).

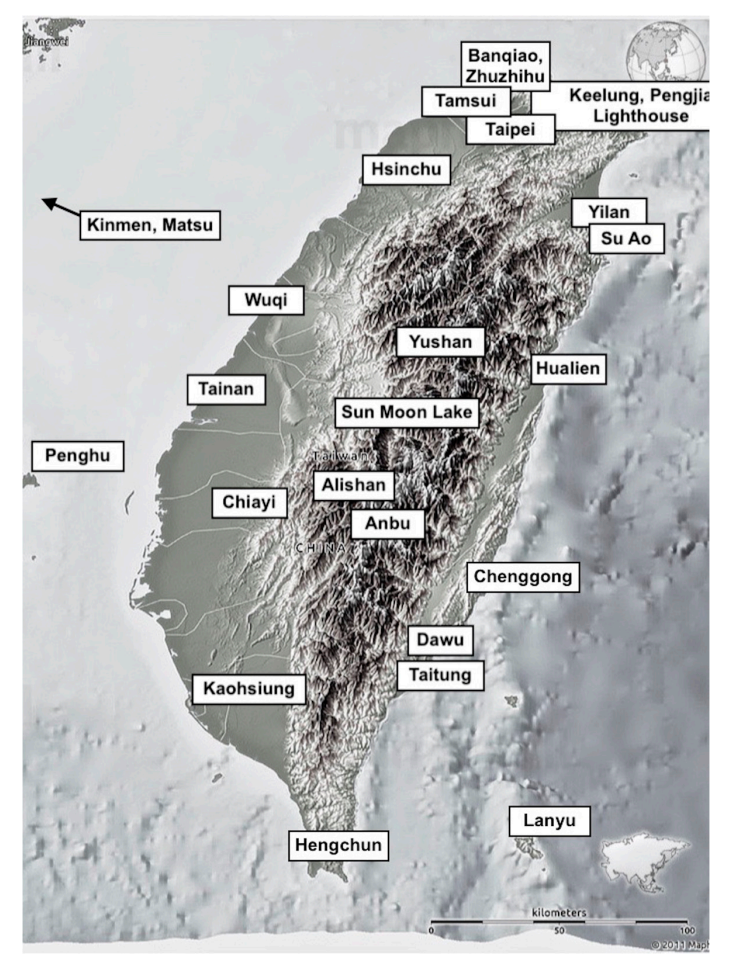

Figure 5. Taiwanese weather stations where temperature, rainfall, soil, and vegetation data were used to derive environmental and ethnographic projections $[20,88]$. 
Environmental calculations were derived from average temperature and rainfall data from the early 2000s as well as soil type, vegetation, modeled ungulate biomass, elevation, and proximity to the coast. Thus, the Binford projections for Taiwan do not represent accurate environmental conditions of the middle Holocene. Rather, this information offers a frame of reference for foraging lifeways that are plausible for a warm, mountainous island setting and can be assessed using more direct lines of evidence such as paleoclimatic records and archaeological information. This paper selected the following subsistence related variables from the Binford database [88].

a. WHUNTP/WGATHP/WFISHP: Expected percentage of hunting, gathering, and fishing/aquatic resources derived from ethnographically known hunter-gatherer groups who reside in habitats with similar environmental characteristics.

b. SUBSPE: Ordinal classification of projected foraging subsistence specialty. $1=$ primarily hunting or dependence on terrestrial animals; 2 = gathering or dependence on terrestrial plants; 3 = primarily fishing or dependence on aquatic prey.

c. SUBDIV: An index of foraging diversity or 'evenness' that is calculated using Simpson's diversity index (see below for details of calculation). Expressed as a decimal value between 0 and 1 in which values approaching 1 indicate less evenness or more specialization.

\section{Results}

\subsection{Foraging Subsistence Projections and Preferred Wild Prey in Taiwan}

To estimate foraging subsistence focus, SUBSPE, an ordinal variable is calculated for predominant expected dependence upon foraging modes available in the habitat. Options include terrestrial animal focus $(1=$ hunting), terrestrial plants $(2=$ gathering $)$, and aquatic species $(3=$ fishing/shellfish). For example, the SUBSPE for the weather station located near the Tamsui estuary in the north estimated more than $50 \%$ dependence on aquatic food resources. Therefore, SUBSPE was designated as " 3 " for Tamsui. Overall, the Binford projections for Taiwan foraging subsistence indicate that, if Paleolithic hunter gatherers were behaving as they did in similar habitats during the ethnographic present, most groups would be focused on fishing/aquatic resources (Figure 6). The only exceptions are in the central or coastal mountains, which are predicted to rely mostly on hunting.

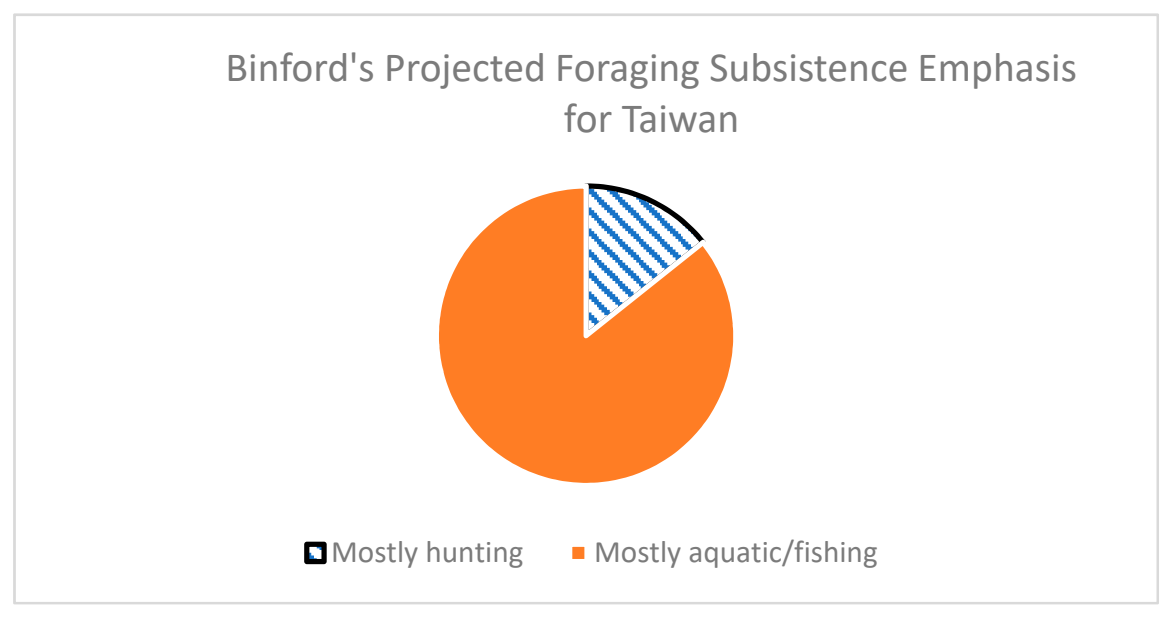

Figure 6. Binford's expected subsistence emphasis (SUBSPE) for 27 Taiwanese weather stations.

In his worldwide analysis of hunter gatherer subsistence patterns, Binford [20] noted several interesting generalizations about aquatic-focused foraging. Usually, early stage niche broadening is accomplished by including more terrestrial plant foods (often those requiring additional processing). Binford notes that the majority of aquatically focused hunter-gatherer groups worldwide are situated in forest plant communities that generally offer little accessible plant food for hunter-gatherers [20]: 
“...Human dependence upon aquatic resources occurs either as a supplement to a plant-based strategy or as the primary strategy in environments that prohibit plant-based subsistence options. The shift to a highly aquatic focus happens only in cases where edible plants are rare". The low frequency of edible endemic Taiwanese forest species [89] and corresponding predominance of non-native plant food species in traditional diets of Taiwan's indigenous Amis and Paiwan peoples [90,91] are consistent with Binford's generalization: specialization in aquatic foraging occurred early in Taiwan due to the lack of terrestrial plant food species. Most edible plant foods endemic to the island that are known today include ferns, fungi, fruit, and algae or kelp.

Binford's projections for Taiwan's foraging subsistence focus by percentage (Figure 7) indicate that the distance to the coast is a predictor of aquatic specialization, with mountain sites such as Alishan, Sun Moon Lake, and Yushan comprising the highest terrestrial hunting focus. The outlier Chiayi is distant from the coast, but the high aquatic focus could be influenced by a local river. Notably, no Taiwanese site was modeled to have greater than $37 \%$ dependence on terrestrial plant foods.

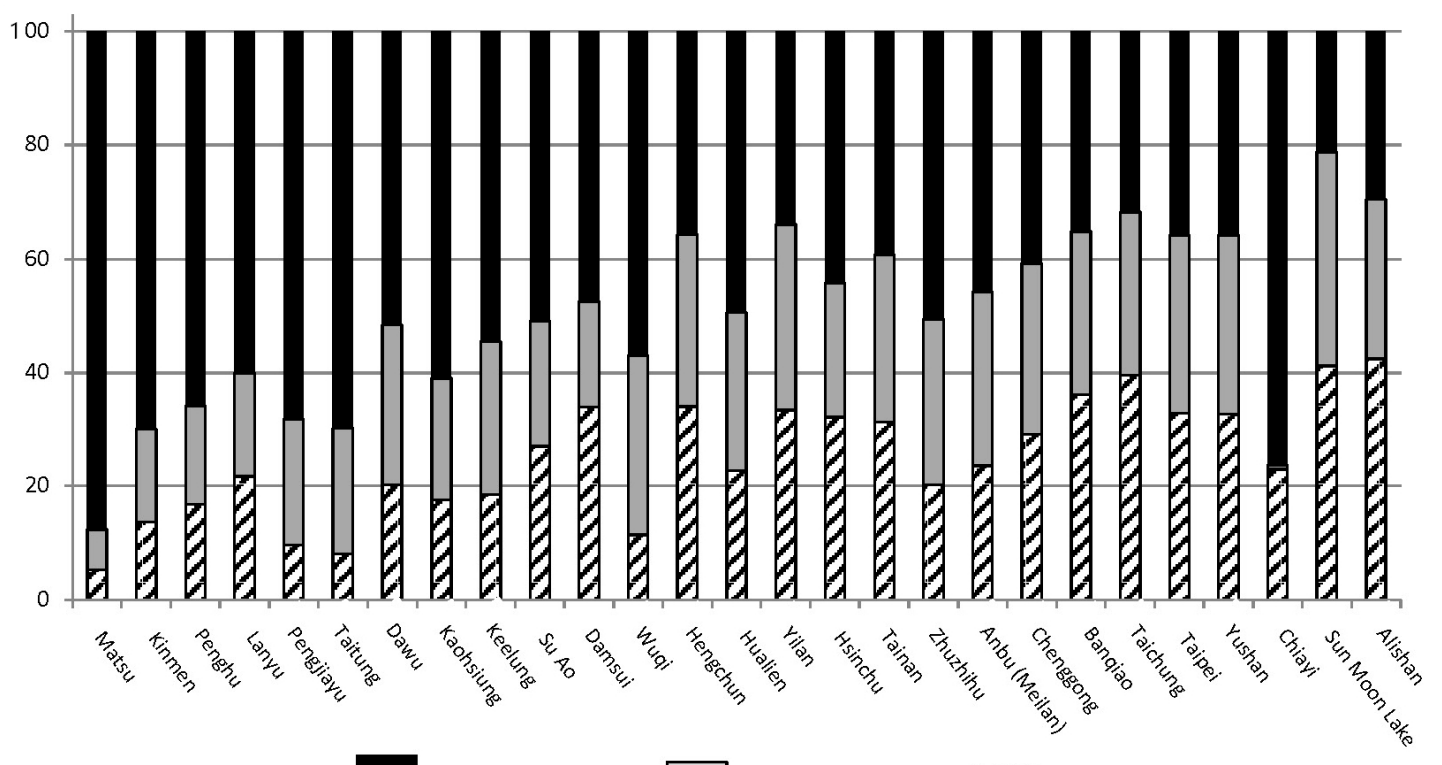

Fishing

Gathering $\$ \$$ Hunting

Figure 7. Binford's estimated percent contribution to foraging subsistence by distance to coast.

Foraging niche breadth can be characterized as the degree of evenness between relative reliance on terrestrial animals, plants, and aquatic foods: more evenness indicates a generalized and broad niche. To make an estimate for Taiwan foraging, Simpson's diversity index [92] (originally calculated for biodiversity) is used to measure evenness, defined as the relative degree of reliance of hunting, gathering, and aquatic subsistence for each location. This calculation is made using variables that reflect 'packed' population conditions that are referable to those of the ethnographic present, $>9.1$ persons $/ \mathrm{km}^{2}$ (Binford's WHUNTP, WGATHP, and WFISHP variables) [20,88]. The diversity index is expressed as $\mathrm{D}=\Sigma[\mathrm{n} / \mathrm{N}]^{2}$ in which $\mathrm{n}=$ the total number of organisms of a particular species and $\mathrm{N}=$ the total number of organisms of all species. The equation used in this calculation is: Foraging diversity $[D]=(\text { WHUNTP }+ \text { WGATHP }+ \text { WFISHP })^{2} / 10,000$. The value D ranges between 0 and 1 , where 0 represents infinite diversity and 1, no diversity. Thus a value closer to 1 indicates un-evenness and a high degree of specialization. Thus, the percentage dependence on either hunting, gathering, or fishing is substituted for the number of organisms in the diet, and the result is divided by 10,000 for ease of viewing.

Figure 8 indicates that foraging is specialized upon fish/aquatics near the coast, then shifts inland to mountain-oriented hunting. Again, the outlier is Chiayi, possibly influenced by a large freshwater river with migratory catadromous fish. Overall, the Taiwan foraging diversity projection reflects Binford's expectation that niche specialization may occur in groups that are primarily dependent 
upon aquatic resources under nonpacked conditions, where there are few or no wealth or rank differentials [20]. Furthermore, Paleolithic population densities are likely to have increased over time as a consequence of the predictability of aquatic resources: Binford's database of known foragers indicates that aquatic-dependent groups have higher population densities (17.9 persons per 100 square kilometers) than plant gatherers (10.5 persons) or hunters (3.4 persons) [20].

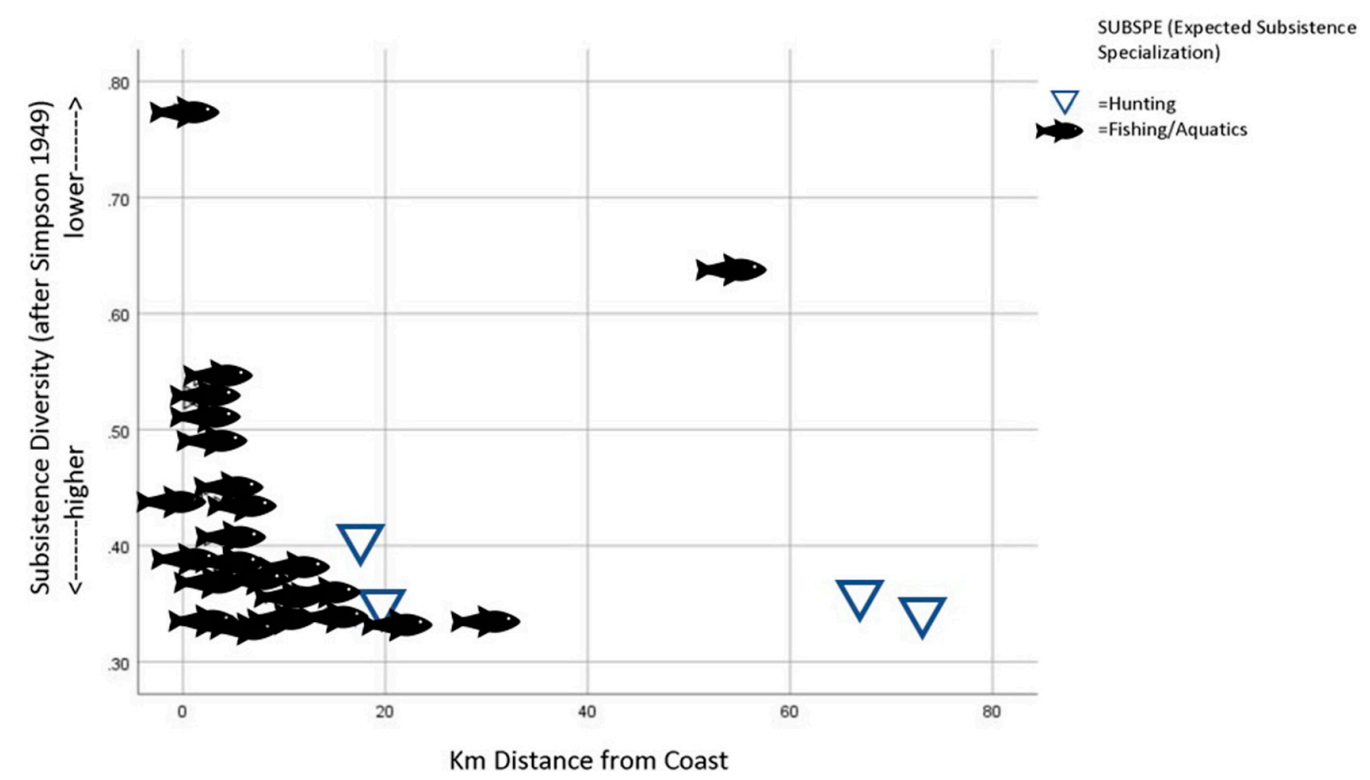

Figure 8. Binford's $[20,88]$ estimated diversity of foraging subsistence for Taiwan, assessed by distance from the coast, calculated using Simpson's diversity index [92].

Binford's projections from global hunting and gathering data have interesting implications for the evolutionary pathway of foraging in Paleolithic Taiwan. During the early period of c. 20-10,000 BP, foraging groups moving to the island, most likely over land, added aquatic resources as a niche broadening tactic. With the onset of Holocene conditions and population infilling from c. 10,000-6000 BP, foragers became specialized in aquatic foods. Shellfish and other nearshore/wetland species required little effort to harvest and could be taken by children and the elderly. Through specialized technology (boats, nets, spears, harpoons), large bodied offshore species could be pursued. With growing population densities and competition for coastal resources, the aquatic focused niche became filled and foraging shifted inland toward montane terrestrial resources, with ungulates preferred. Taiwan's rugged mountain uplands typically require arduous foot travel from the coast, which would likely necessitate a near full-time commitment to hunting.

Projections from reference information are consistent with post-ecological release described by the niche variation hypothesis: early Paleolithic human migration to the island allowed for niche-broadening over time and increasing among-group variation toward either mountain hunting or coastal fishing. These niches eventually became specialized to form the regionally diverse Persistent Upper Paleolithic foraging adaptation of Taiwan. These projections allow us to estimate rank order of the foragers' preferred wild prey as follows.

If the prey rankings in Table 1 are correct, then high ranked habitats for foragers were coastal, lake, and wetland, followed by coastal plain, piedmont, and forested uplands. The last habitats to be occupied were predicted as high mountain regions that are sub-alpine today and likely forested during the warmer mid-Holocene. Projections from reference information are consistent with post-ecological release described by the niche variation hypothesis: early Paleolithic human migration to the island allowed for niche-broadening over time and increasing among-group variation toward either mountain hunting or coastal fishing. These niches eventually became specialized to form the regionally diverse Persistent Upper Paleolithic foraging adaptation of Taiwan. 
Table 1. Estimated ranking of preferred prey and habitat, Upper Paleolithic foragers.

\begin{tabular}{ll}
\hline \multicolumn{1}{c}{ Prey Type Rank Order } & \multicolumn{1}{c}{ Habitat Type } \\
\hline 1. Shellfish, nearshore fish including migratory catadromous species, waterfowl & Littoral/estuary/delta wetland/lake basin \\
\hline 2. artiodactyls (deer, sambar, muntjac, serow), perissodactyls (boar) & Coastal plain, forested mountains, valleys \\
\hline 3. Deep water fish, turtles, marine mammals & Pelagic/offshore, islets \\
\hline 4. Arboreal and burrowing prey (macaque, pangolin, flying squirrel, and birds) & Forested valleys, piedmont and uplands \\
\hline 5. Resident river fish, catadromous species, turtles & Riverine/inland \\
\hline 6. Wild plants (geophytes, ferns, fungus, fruit, algae) & Forested valleys, piedmont and uplands \\
\hline
\end{tabular}

\subsection{Transitional Neolithic Paleoenvironments and Archaeology}

Against this heterogeneous and dynamic environmental and cultural backdrop, the first evidence of sedentized agriculture appears in Taiwan between 6000 and 5000 BP during what is termed the Dapenkeng (previously Tap'enkeng) period $[4,10,11,15-17,67,78,93]$. Saltwater inundation and the loss of low lying arable lands and productive wetlands on China's southeast margin could have created conditions favoring sea-faring over further investment in local agriculture, leading to migrations across the Taiwan Strait [5]. Regional Neolithic variants emerged early (see Figure 4, above), as evidenced by the Shuntanpu Early Culture in the north, Niumatou Early Culture in the central region, and Guoye in the south. At the time of writing, the influence of Paleolithic regionalization on early Neolithic cultures is not known.

Dapenkeng period sites are mostly distributed on the southern, northern, and eastern coasts around the island [16]. Hung and Carson [4] noted that today's alluvial plains accumulated mostly after 3000 BC, especially along the western coastline. Thus, most early Dapenkeng communities overlooked swampy nearshore environments, which have since became in-filled with alluvium $[4,67]$. Archaeological materials from the Dapenkeng type site (c. 5600 BP) near Tamsui in northern Taiwan include cord-marked pottery, polished stone adzes and harvesting knives, drilled slate projectile points, and baked clay spindle whorls [10-12]. Pottery is thick walled, sand-tempered and cord marked; stone adzes are quadrangular in cross-section and usually polished. Pecked pebbles were possibly used as net sinkers, and distinctive bark-cloth beaters were used to create raw material for clothing and other purposes [93]. Other cultural traits of Shuntanpu Early Culture include site placement on coastal and stream terraces, and planned semisedentary communities with extensive ditch and well construction and ash pits [4,10,11,93-95]. Faunal remains from the Dapenkeng type site include fish, shellfish, and mammal remains [10,89]. Macrobotanical evidence of millet and rice has also been found at multiple Shuntanpu sites, along with irrigation features [78,93].

Niumatou Early Culture sites (c. 5600-4200 BP) in the Taichung Basin of central Taiwan include the large Anhe site. Niumatou culture is remarkable for extensive cemeteries that indicate a wide range of ages and sexes, and tooth extraction practices [96]. Well-crafted burial objects include sandy paste ceramics (both red and occasionally black wares) such as dou double and triple cups, tapa bark beaters, and nephrite adzes and jewelry [ibid]. The ceramics have strong affinities to Southeast Chinese wares across the strait, indicating continued cultural interchange [78]. Sika deer, muntjac, small fish, shark, and shellfish remains indicate a mix of terrestrial and aquatic foods, along with macrobotanical evidence for rice $[78,96]$.

In the south, recent excavations near Tainan have revealed a major Neolithic site complex at Nan-kuan-li and Nan-kuan-li East. The Dapenkeng period/Guoye phase dates to between 5000 and 4300 BP $[16,67,97]$. Site placement was preferentially on plains, terraces, and low hills facing wetlands $[67,78]$. Material evidence includes a robust assemblage of soft pottery of red and brown ware, rounded bottoms and feet, and decorations from cord-marking or comb-incised or shell-impression $[67,97]$. The toolkit is dominated by wood working and farming implements such as polished stone hoes, axes, adzes, and chisels. A small number of hoes are fashioned of thick shell. Drilled stone knives, stone projectile points, fishnet sinkers, and tapa bark beaters are common [67,97]. The consistent presence of olivine basalt from Penghu off the southwest coast indicates a strong trade connection 
with people of that island complex throughout the Guoye period [67]. Bone, tooth, and shell were used for drills, needles, jewelry, and cutting implements [ibid]. Faunal remains were well preserved, with shellfish predominant as well as a variety of sharks and other cartilaginous fish like stingray as well as bony fish from estuarine and pelagic habitats [16,97]. Reptiles include tortoise, soft shell turtle, and snake, and wild mammals include rat, sika deer, muntjac, Formosan badger, Formosan wild boar, and a small species of wild cat. Domesticated dog bones are found in midden settings as well as buried intentionally [67]. Plant remains include diverse wild species, dominated by chinaberry tree [Melia azedarach] as well as nigaki shrub (Picrasma quassioides) and hackberry tree (Celtis sinensis) [16]. Seeds and fruits may have been used for food, similar to Donghulin and other transitional Neolithic sites in China [98-100]. Both carbonized rice and millet remains have been found, with millet somewhat earlier in the sequence [67]. The local landrace of rice may have been domesticated locally based on seed morphology [67], whereas foxtail millet (Setaria spp.) likely arrived from China.

On the east coast, Dapenkeng period sites are smaller, consisting of either nephrite quarries or concentrations of cord-marked soft pottery below later Neolithic settlements. No settlements of the size and complexity of the western and southern regions have yet to be discovered [78], thus subsistence evidence is not sufficient for detailed discussion yet.

Overall, archaeological evidence suggests that the subsistence niche during the transitional Neolithic was broadly based. Evidence for fishing and shellfish collection predominates over farming, hunting, and collecting [67]. Taiwan's first farmers employed diverse cultivation techniques for two crop types: dryland (millet) and wet paddy (rice), which suggests influences both from the northern and eastern regions of mainland China $[67,100]$. Other crops such as geophytes and tree crops also may have been cultivated. Sizeable communities, burial grounds, and irrigation features along with distinctive vessel shapes and tapa bark beaters and genetic affinities of millet and rice suggest ongoing influences and interchanges with the cultures of what are now the Fujian coast and Guangdong/Pearl River delta regions in southeast China [78].

These data suggest that rats, mustelids, reptiles, and cats were part of the earliest Neolithic diet. Although differences in the preservational environment could allow for better species identification in Neolithic depositional contexts, this listing is broader than the Paleolithic and includes more genera and smaller body size prey. This, in combination with crop cultivation, allows us to estimate the rank order of the farmer-fisher's preferred prey as follows (the term 'prey' is used generally here, including cultigens).

If the prey rankings in Table 2 are correct, then high ranked habitats for Taiwan's first farmers were initially coastal, lake, and wetland adjacent to coastal plains. These habitats required to practice cultivation and access wild aquatic prey are distributed on the northwestern, west, and southern areas of the island. Piedmont, forested uplands, and the steep east coast would have been occupied after preferred habitats became infilled. The least desirable habitats to be used consistently by early farmers have been predicted as high mountain regions that are sub-alpine today and likely forested during the warmer mid-Holocene.

Table 2. Estimated ranking of preferred prey and habitat, Incipient Neolithic farmer-fishers.

\begin{tabular}{ll}
\hline \multicolumn{1}{c}{ Prey Type Rank Order } & \multicolumn{1}{c}{ Habitat Type } \\
\hline 1. Shellfish, nearshore fish including migratory catadromous species, waterfowl & Littoral/estuary/delta wetland/lake basin \\
\hline 2. artiodactyls (deer, sambar, muntjac, serow), perissodactyls (boar) & Coastal plain, forested mountains, valleys \\
\hline 3. Cultigens and edible weeds & Coastal plain, valleys \\
\hline 4. Arboreal and burrowing prey (macaque, pangolin, flying squirrel, and birds) & Forested valleys, piedmont and uplands \\
\hline 5. Resident river fish, catadromous species, turtles & Riverine/inland \\
\hline 6. Deep water fish, turtles, marine mammals & Pelagic/offshore, islets \\
\hline 7. Wild plants (geophytes, ferns, fungus, fruit, algae) & Forested valleys, piedmont and uplands \\
\hline
\end{tabular}




\section{Discussion}

The estimated prey rankings indicate that the overlap in habitat preference of foragers and farmer-fishers includes coastal plains, lakes, and other flat wetland areas with easy access to the coast or major bodies of water. These are located in the northwest, west, and south. More mobile foragers would have had an edge when exploiting the rugged east coast or the mountain uplands. The working hypothesis prediction regarding the earliest Neolithic in Taiwan can now be refined as follows.

If the assumptions of the PCM hold, high ranked aquatic prey (e.g., large shellfish and other nearshore species) and ungulates should rapidly become depleted in highly ranked habitats. The harvest of lower ranked prey such as small body size mammals and reptiles, and wild plants, should become more common. This process would end when foragers decide to adopt agricultural practices, or migrate to the east coast or mountain habitats.

If assumptions of an IFD with Allee effects hold, the flatlands of the northwest, west, and south adjacent to the coast should see increases in encounter rates for sika deer, pigs, and muntjac, which do well with more heterogeneous vegetation and successional communities associated with farming [71]. It is less clear if farming and/or intensified foraging would improve encounter rates with near shore aquatic prey, although in upland lake habitats, indigenous Taiwanese create fish islands of bamboo and thatching to improve the survival of young fry. The antiquity of this practice is not known, but it is reasonable. Given the scarcity of edible wild plant options in Taiwan, the adoption of crops would have provided a niche construction tactic to increase energetic returns per area. Edible commensal weeds that volunteer in the fields likely provided a dietary complement [90].

This process has important implications for predicting the ways that feedbacks in the consequences of resource/land use may shape interactions in diverse subsistence strategies, settlement, and social interactions. If, as modeled by Binford's database, the Persistent Upper Paleolithic foraging niche was specialized in either coastal or mountain resources, foragers of agriculturally desirable regions such as the northwestern, western, and southern coastal floodplains, flat, well-drained areas near river confluences, and terraces would have been affected the earliest by immigrating farmers. Competition for wild resources needed by foragers would have been direct, continuous, and increasing as farmers settled and expanded. The prey choice model predicts immediate and unidirectional drops in preferred prey, which would result in a 'push' for foragers in these regions to move, or adopt unfamiliar crops and cultivation techniques. The IFD with Allee effects predicts an initial increase in encounters with preferred prey due to beneficial niche construction activities, which might delay-though not for long - the thresholds for foragers to cultivate or move. Another consideration is the 'pull' associated with forager-farmer social interactions that rapidly reduced language barriers and other obstacles to knowledge exchange.

A more nuanced process is expected for areas not initially settled by early Neolithic agriculturalists in the mountain uplands, islets, and rugged east coast. Here, processes predicted by the PCM and the IFD with Allee effects were delayed. Competitive pressure on wild resources needed by foragers would initially have been indirect, gradual, and sporadic, most likely driven by the movements of foragers in response to immigrating farmers rather than by the farmers themselves. The 'pull' to expand niche breadth by adopting crops and cultivation knowledge would be weaker, with crop types adopted in ascending order of cost and risk to existing foraging lifeways ( $\mathrm{Yu}$, in press). Figure 9 shows areas preferred by farmers for settlement and variability in expected modes of competitive pressure on wild resources needed by foragers. 


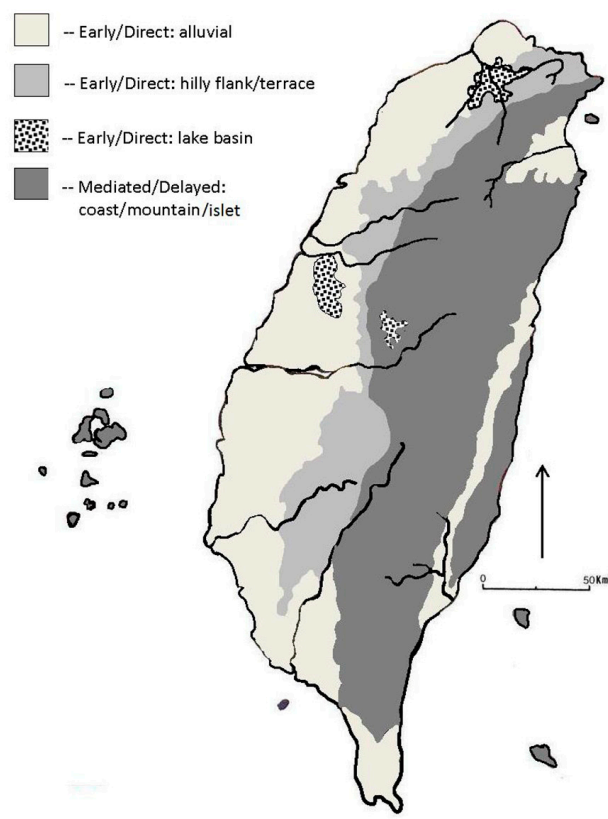

Figure 9. Geographic representation of Taiwan's modes of variable invasive pressure on wild resources associated with Neolithic onset, based on Binford's subsistence projections [37] used by permission.

In sum, niche variation theory, the prey choice model, and the IFD with Allee characteristics are useful heuristic tools for the latest Paleolithic and earliest Neolithic of Taiwan when combined with macroecological reference information about late-stage foraging. However, is an important difference in extrapolating theoretical predictions derived from non-humans for human groups: our flexible and constructible niche. Neolithic immigrants initially enhanced vegetative diversity through cultivation, potentially increasing encounter rates with high ranking prey. Farmers also brought along novel food species such as seed and possibly tuber crops, thus foragers under resource pressure could offset narrowing niche options by adopting crops that they deemed the least costly to mobility needed for acquiring preferred wild resources [37]. A working chronological reconstruction of Taiwan's Neolithic transition follows:

1. Early Paleolithic foragers migrated to Taiwan from the mainland c. 20,000 years ago, moving into new territory under conditions of ecological release.

2. Niche variation theory predicts an expansion of foraging niche breadth, increasing among-group variation within the niche. By the Persistent Upper Paleolithic, foraging niches divided into two specialized modes: either aquatic resources or mountain hunting.

3. The arrival and first dispersal of Neolithic Chinese farmers caused farmer-forager competition for wild resources, especially aquatic, in flat areas near coasts and wetlands. The prey choice model predicts that the niche overlap would lead to reductions in preferred prey and resource depression, whereas the IFD with Allee effects predicts that niche constriction could have increased encounter rates with preferred prey, at least in the beginning.

4. Foragers choosing to remain in colonized areas responded adaptively by taking low-ranked prey, then including low-ranked, low-cost cultigens in the diet, expanding the foraging niche temporarily (Figure 10). The PCM predicts this would have occurred rapidly; the IFD predicts a delay due to the beneficial effects of niche construction.

5. This phenomenon occurred early and rapidly in coastal areas and neighboring flat regions that were favorable to arriving farmers, then dispersed into more distant mountain uplands and the east coast as demographic packing continued.

6. The transition was more gradual in the central mountains and east coast. Foragers who opted to move away from farmer interactions may have encountered forager-forager competition and 
resource depression in those areas, and demographic growth fueled a cycle that ultimately ended full-time hunting and gathering across Taiwan.

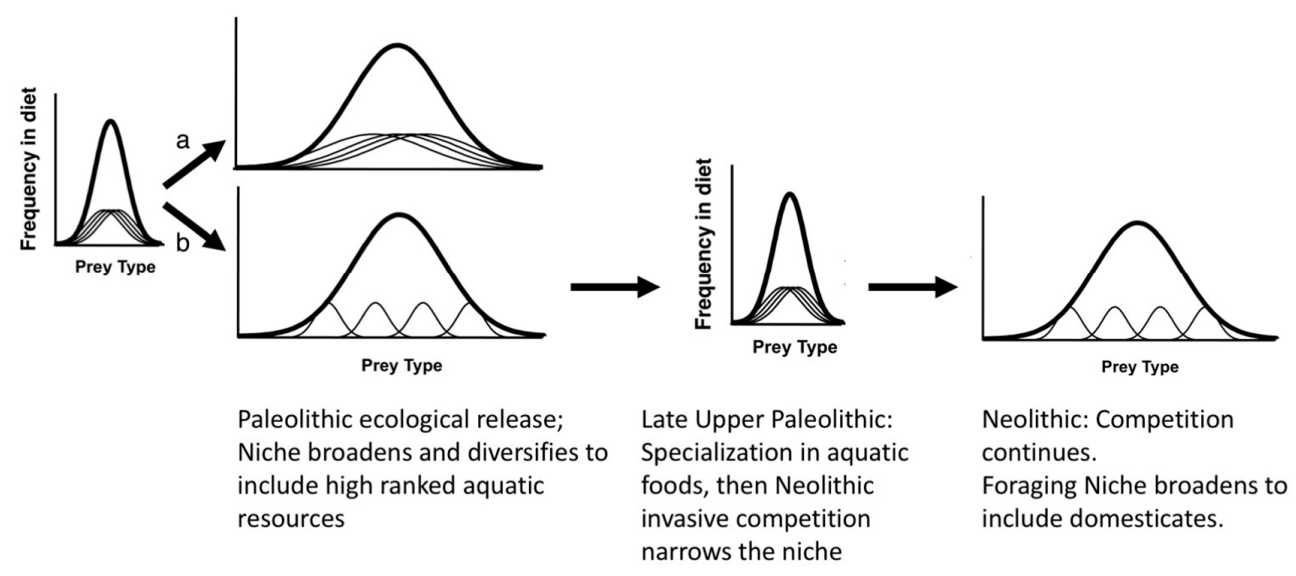

Figure 10. Schematic of the Niche Variation Theory applied to Neolithic impacts on foraging niche (adapted from [18], used by permission). (a) Inter-group niche breadths expand, resulting in no increased niche variation among individuals. (b) Individual group niche breadths remain limited, then groups diverge to increase among-group variation.

This qualitative assessment of the PCM and IFD has utility for making predictive statements about timing and intensity of the Taiwan Neolithic transition, particularly from the foraging perspective. In fact, this finding explains why foraging persisted in the mountains and along the east coast, even into the Middle Neolithic. The eventual demise of the Paleolithic lifeway can be predicted once the foraging niche could no longer be expanded through the addition of low cost options, or prolonged through niche construction [37]. Even after the full commitment to cultivation was made, selective forces actively favored a prolonged stage of mixed economies that included wild prey, commensal species, and vegeculture resources alongside cereal cultigens. This moderate risk/moderate yield mixed strategy with Neolithic roots is seen in Japan, Southeast China, and other areas worldwide, and played a role in oceanic migrations. The mixed strategy maintains diverse and nutritious diets, sustains crop diversity and wild resource viability, reduces travel and processing costs, and hedges against risk and loss [1].

The limitations of testing this approach for the Taiwan Neolithic transition include the imperfect preservation of material evidence for foraging subsistence behaviors, and therefore small sample sizes and lack of a basis for strong inferential arguments. However, as the rate of discovery of well-dated early sites increases, the likelihood of new Persistent Upper Paleolithic and Dapenkeng sites-and therefore the sample size-is increasing. The PCM and IFD working scenarios could be assessed using various classes of archaeological evidence as new data become available (Table 3).

Table 3. Potential lines of evidence to assess Prey Choice Model and Ideal Free Distribution expectations.

\begin{tabular}{|c|c|}
\hline Model/Prediction & $\begin{array}{l}\text { Categories of Evidence } \\
\text { (Incipient NEOLITHIC, c. 6000-5000 BP) }\end{array}$ \\
\hline 1. Prey Choice Model/Resource Depression & $\begin{array}{l}\text { Subsistence: Decreases in frequency, diversity, age, and size of high ranked prey species relative to } \\
\text { lower ranked prey. } \\
\text { Technology: Increased processing tools and features such as ovens and graters. } \\
\text { Settlement: Temporal and geographic overlap between Paleolithic and Neolithic sites in flatlands near } \\
\text { the coast. } \\
\text { Low frequency of earliest Neolithic sites in mountain uplands, islets, and east coast. }\end{array}$ \\
\hline $\begin{array}{l}\text { 2. IFD/Allee Effects/Niche Construction and } \\
\text { Resource Benefits }\end{array}$ & $\begin{array}{l}\text { Subsistence: Initially, increases in frequency, diversity, age, and size of highly ranked prey types } \\
\text { relative to lower ranked prey. Could decrease over time after population rises. } \\
\text { Technology: Few processing tools and features such as ovens and graters; more procurement tools } \\
\text { (e.g., fishing and hunting equipment). } \\
\text { Settlement: Temporal and geographic overlap between Paleolithic and Neolithic sites in flatlands near } \\
\text { the coast; initial increase in Paleolithic sites close to Neolithic settlements, then replacement by } \\
\text { agricultural sites. } \\
\text { Low frequency of earliest Neolithic sites in mountain uplands, islets, and east coast. }\end{array}$ \\
\hline
\end{tabular}




\section{Conclusions}

A major challenge in assessing hypotheses for this time period in Taiwan is the lack of means to distinguish early Neolithic sites from sites in which Paleolithic foragers were experimenting with cultivation. Although the presence of ceramics is one indicator of farming, some of Taiwan's 'last foragers' may have been able to obtain ceramics or ceramic manufacturing techniques while maintaining a mostly foraging lifestyle. Across the strait in SE China, a prolonged Neolithic transition included coastally-adapted hunter-gatherers who used ceramics, lived in semi-sedentary villages, and created cemeteries as late as 3000 BP $[17,101-103]$.

Nevertheless, predictions derived from the niche variation theory, the prey choice model, and the IFD with Allee effects allow us to explore alternative processes for the incipient Neolithic. Taiwan's geographic position and diverse habitats and foraging opportunities ensured that the transition to farming was neither simple nor linear, but may be predicted. With the increase in chronometrically dated sites from this time period, archeofauna and other lines of evidence can be used to determine alternative explanations for the ways that Taiwan's Upper Paleolithic foragers and Chinese Neolithic farmer-fishers evaluated the costs and benefits and made strategic adjustments to their subsistence niche as they encountered new food types and each other to create a mosaic of potential habitat choices. If the PCM is supported, the ability to adjust prey choice and niche breadth ensured that the Persistent Upper Paleolithic endured in areas remote from farmers as late as $5000 \mathrm{BP}$, and likely even later. The IFD with Allee effects also accommodates prolonged foraging in areas where increased diversity of habitat succession and plant communities arose from the mosaic created by cultivation.

On the Neolithic side, farmers continued to include wild and semi-domesticated species alongside crops, with aquatic resources as a major, if not the most important dietary staple. The role of prey choice, niche, and habitat preferences in invasive dispersal and native adaptations is central to understanding variability in crop adoption by foragers, helping to frame the process in an evolutionary framework that places the foraging legacy in a key position for influencing evolutionary transitions to agriculture and later pathways to complexity.

Funding: This research was funded by the J. William Fulbright Foreign Scholarship Program and the Taiwan Foundation for Scholarly Exchange.

Acknowledgments: Research associated with this study was generously supported by a Fulbright Senior Researcher Fellowship under the robust support of Fulbright Taiwan. Maa-ling CHEN (National Taiwan University) shared archaeological wisdom and sources, helped me to navigate the ins and outs of living and traveling in Taiwan, generously invited me to archaeology classes, and facilitated the translation of reports. Chen, Chia-yu HU, and Hsiu-fang TSAI arranged for a viewing of the Dapenkeng type site artifacts and records at the National Taiwan Museum of Anthropology in Taipei. Fu CHUN, Mei-Zhen YE, and Kun-Hsiu LEE, all from the National Taiwan Museum of Prehistory in Taitung, facilitated a tour of the Baxiandong Paleolithic site and provided useful technical reports. Yu-Mei CHEN and Yi-Chang LIU of Academia Sinica's Institute of History and Philology kindly hosted a lecture and provided invaluable technical materials and advice regarding Taiwanese prehistory. Thanks to Kazunobu IKEYA for permission to cite from his important works on Asian hunting and gathering societies, and Daniel Bolnick for permission to adapt figures from his important work on evolutionary aspects of niche and invasions. My appreciation goes to the peer reviewers whose comments strengthened and clarified the theoretical concepts in the paper. My father, J. S. YU, translated the literature sources and during scholarly discussions, assisted with reverse translation and transcription of recordings, and provided important insights about Taiwanese traditional crops from personal and family experience. I am profoundly grateful for his help, his tireless and humorous companionship, and his belief in the value of scientific anthropological research for the good of all human societies.

Conflicts of Interest: The author declares no conflict of interest.

\section{References}

1. Smith, B.D. Low-level food production. J. Archaeolog. Res. 2001, 9, 1-43. [CrossRef]

2. Ikeya, K.; Ogawa, H.; Mitchell, P. (Eds.) Interactions between Hunter-Gatherers and Farmers: From Prehistory to Present; National Museum of Ethnology: Osaka, Japan, 2009; ISBN 9784901906654. 
3. Winterhalder, B.; Kennett, D.H. Behavioral ecology and the transition from hunting and gathering to agriculture. In Behavioral Ecology and the Transition to Agriculture; Kennett, D., Winterhalder, B., Eds.; University of California Press: Berkeley, CA, USA, 2006; pp. 1-21, ISBN 9780520246478.

4. Hung, H.C.; Carson, M.T. Foragers, fishers and farmers: Origins of the Taiwanese Neolithic. Antiquity 2014, 88,1115-1131. Available online: https://www.cambridge.org/core/journals/antiquity/article/foragers-fishersand-farmers-origins-of-the-taiwanese-neolithic/7B50C25B6298EB3AEABE1E8EEFD030C8 (accessed on 15 April 2020). [CrossRef]

5. Peltier, W.R. On eustatic sea level history: Last Glacial Maximum to Holocene. Quat. Sci. Rev. 2002, 21, 377-396. Available online: https://www.sciencedirect.com/science/article/pii/S0277379101000841 (accessed on 15 April 2020). [CrossRef]

6. Rollett, B.V.; Zheng, Z.; Yue, Y. Holocene sea-level change and the emergence of Neolithic seafaring in the Fuzhou Basin (Fujian, China). Quat. Sci. Rev. 2011, 30, 788-797. Available online: https: //www.sciencedirect.com/science/article/pii/S0277379111000308 (accessed on 15 April 2020). [CrossRef]

7. Bulbeck, D. An integrated perspective on the Austronesian diaspora: The switch from cereal agriculture to maritime foraging in the colonisation of Island Southeast Asia. Aust. Archaeol. 2008, 67, 31-51. Available online: https://www.tandfonline.com/doi/abs/10.1080/03122417.2008.11681877 (accessed on 15 April 2020). [CrossRef]

8. Bellwood, P. Southeast China and the Prehistory of the Austronesians. In Lost Maritime Cultures: China and the Pacific; Jiao, T.L., Ed.; Bishop Museum Press: Honolulu, HI, USA, 2007; pp. 36-53, ISBN 9781581780635.

9. Bellwood, P. Formosan prehistory and Austronesian dispersal. In Austronesian Taiwan: Linguistics, History, Ethnology, Prehistory; Blundell, D., Ed.; N. W. Lin Foundation for Culture and Educational Endowment: Berkeley, CA, USA, 2009; pp. 336-364, ISBN 986-8537819.

10. Blust, R. The Austronesian Languages; Research School of Pacific and Asian Studies: Canberra, Australia, 2009; ISBN 9780858836020.

11. Chang, K.C. The Neolithic Taiwan Strait. Kaogu 1989, 6, 569.

12. Chang, K.C. Fengbitou, Tapenkeng, and the Prehistory of Taiwan; Yale University Publications in Anthropology: New Haven, CT, USA, 1969; ISBN 9781444335293.

13. Chang, K.C.; Goodenough, W.H. Archaeology of southeastern China and its bearing on the Austronesian homeland. In Prehistoric Settlement of the Pacific; Goodenough, W.H., Ed.; American Philosophical Society: Philadelphia, PA, USA, 1996; pp. 28-35, ISBN 9780871698650.

14. Pawley, A. The Austronesian dispersal: Languages, technologies and people. In Examining the Farming/language Dispersal Hypothesis; Bellwood, P., Renfrew, C., Eds.; MacDonald Institute for Archaeological Research: Cambridge, UK, 2002; pp. 251-273, ISBN 9781902937205.

15. Tsang, C.H. Recent discoveries at the Tapenkeng Culture Sites in Taiwan: Implications for the Problem of Austronesian Origins. In The Peopling of East Asia: Putting Together Archaeology, Linguistics, and Genetics; Sagart, L., Blench, R., Sanchez-Mazas, A., Eds.; Routledge Curzon: New York, NY, USA, 2005; pp. 63-73, ISBN 9781138862234.

16. Bellwood, P. Taiwan and the Prehistory of the Austronesian-Speaking Peoples. In Ethnos, Geography and Development: An Interdisciplinary Approach to Human-Environment Relations; Kuan, D.W., Ed.; Shung Ye Museum of Formosan Aborigines: Taipei, Taiwan, 2017; pp. 3-33, ISBN 9789869239639.

17. Li, K.T. First Farmers and Their Coastal Adaptation in Prehistoric Taiwan. In A Companion to Chinese Archaeology; Underhill, A.P., Ed.; Blackwell: Oxford, UK, 2013; pp. 612-633, ISBN 9781444335294.

18. Liu, Y.C. Prehistory and Austronesians in Taiwan: An archaeological perspective. In Austronesian Taiwan: Linguistics, History, Ethnology, Prehistory; Blundell, D., Ed.; N. W. Lin Foundation for Culture and Educational Endowment: Berkeley, CA, USA, 2009; pp. 365-400, ISBN 9868537800.

19. Bolnick, D.I.; Svanbäck, R.; Araújo, M.S.; Persson, L. Comparative support for the niche variation hypothesis that more generalized populations also are more heterogeneous. Proc. Natl. Acad. Sci. USA 2007, 104, 10075-10079. Available online: https://www.pnas.org/content/104/24/10075 (accessed on 15 April 2020). [CrossRef]

20. Fix, A.G.; Shepherd, J.C. Migration and Colonization in Human Microevolution; Cambridge University Press: Cambridge, MA, USA, 1999; Volume 24, ISBN 9780521592062. 
21. Binford, L.R. Constructing Frames of Reference: An Analytical Method for Archaeological Theory Building Using Ethnographic and Environmental Data Sets; University of California Press: Berkeley, CA, USA, 2001; ISBN 0520223934.

22. Svizzero, S. Persistent controversies about the Neolithic Revolution. J. Hist. Archaeol. Anthr. Sci. 2017, 1, 00013. [CrossRef]

23. $\mathrm{Yu}, \mathrm{P}$. Ethnoarchaeology of foraging and the case of the vanishing agriculturalists in the Amazon Basin. J. Anthr. Archaeol. 2015, 38, 59-66. Available online: https://www.sciencedirect.com/science/article/pii/ S0278416514000683 (accessed on 15 April 2020). [CrossRef]

24. Bird, D.W.; O'Connell, J.F. Behavioral ecology and archaeology. J. Archaeol. Res. 2006, 14, 143-188. [CrossRef]

25. Bird, D.W.; O'Connell, J.F. Human behavioral ecology. In Archaeological Theory Today; Hodder, I., Ed.; Polity Press: Cambridge, MA, USA, 2012; pp. 37-61, ISBN 9780745653075.

26. Broughton, J.M.; Cannon, M.D. (Eds.) Evolutionary Ecology and Archaeology; University of Utah Press: Salt Lake City, UT, USA, 2010; ISBN 9780874809350.

27. Codding, B.F.; Bird, D.W. Behavioral ecology and the future of archaeological science. J. Archaeol. Sci. 2015, 56, 9-20. Available online: https://www.sciencedirect.com/science/article/pii/S0305440315000655? casa_token=yVm483vDuhgAAAAA:tPRWrRljxrWNR0_FAJj0Bx03La8Z_ickOJAQI_53Skf_ p7T3chXy8ogpRHbpOmcHromv9ZhaPw (accessed on 5 July 2020). [CrossRef]

28. Lupo, K.D. Evolutionary foraging models in zooarchaeological analysis: Recent applications and future challenges. J. Archaeol. Res. 2007, 15, 143-189. Available online: https://link.springer.com/article/10.1007/ s10814-007-9011-1 (accessed on 5 July 2020). [CrossRef]

29. O'Connell, J.F. Ethnoarchaeology needs a general theory of behavior. J. Archaeol. Res. 1995, 3, $205-255$. [CrossRef]

30. Johnson, A.L. Exploring adaptive variation among hunter-gatherers with Binford's frames of reference. J. Archaeol. Res. 2014, 22, 1-42. Available online: https://link.springer.com/article/10.1007/s10814-013-9068-y (accessed on 15 April 2020). [CrossRef]

31. Fretwell, S.D.; Lucas, H.L. On territorial behavior and other factors influencing habitat distribution in birds. Acta Biotheor. 1969, 19, 16-36. Available online: https://link.springer.com/article/10.1007/BF01601953 (accessed on 5 July 2020). [CrossRef]

32. Kennett, D.J.; Anderson, A.; Winterhalder, B. The Ideal Free Distribution, food production, and the colonization of Oceania. In Behavioral Ecology and the Transition to Agriculture; Kennett, D.J., Winterhalder, B., Eds.; University of California Press: Berkeley, CA, USA, 2009; pp. 265-288, ISBN 9780520246478.

33. Allee, W.C.; Bowen, E. Studies in animal aggregations: Mass protection against colloidal silver among goldfishes. J. Exp. Zool. 1932, 61, 185-207. [CrossRef]

34. Codding, B.F.; Parker, A.K.; Jones, T.L. Territorial behavior among Western North American foragers: Allee effects, within group cooperation, and between group conflict. Quat. Int. 2019, 518, 31-40. Available online: https://www.researchgate.net/publication/321270258_Territorial_behavior_among_ Western_North_American_foragers_Allee_effects_within_group_cooperation_and_between_group_ conflict (accessed on 18 July 2020). [CrossRef]

35. Bliege Bird, R.B.; McGuire, C.; Bird, D.W.; Price, M.H.; Zeanah, D.; Nimmo, D.G. Fire mosaics and habitat choice in nomadic foragers. Proc. Natl. Acad. Sci. USA 2020, 117, 12904-12914. Available online: https://www.pnas.org/content/117/23/12904.short (accessed on 5 July 2020). [CrossRef]

36. Bliege Bird, R.B.; Bird, D.W.; Fernandez, L.E.; Taylor, N.; Taylor, W.; Nimmo, D. Aboriginal burning promotes fine-scale pyrodiversity and native predators in Australia's Western Desert. Biol. Conserv. 2018, 219, 110-118. Available online: https://www.sciencedirect.com/science/article/abs/pii/S0006320717317962 (accessed on 18 July 2020). [CrossRef]

37. Winterhalder, B.; Kennett, D.J.; Grote, M.N.; Bartruff, J. Ideal free settlement of California's northern Channel Islands. J. Anthropol. Archaeol. 2010, 29, 469-490. Available online: https://www.sciencedirect.com/science/ article/abs/pii/S0278416510000425 (accessed on 5 July 2020). [CrossRef]

38. Yu, P. Tempo and mode of Neolithic crop adoption by Paleolithic hunter-gatherers of Taiwan: Ethnoarchaeological and behavioral ecology perspectives. In Hunter-Gatherers in Asia: From Prehistory to Present; Ikeya, K., Nishiaki, Y., Eds.; Senri Ethnological Studies (SES)/National Museum of Ethnography: Osaka, Japan, 2021. (in press) 
39. Elton, C.S. The Ecology of Invasions by Plants and Animals; University of Chicago Press: Chicago, IL, USA, 1958; ISBN 9780521592062.

40. MacArthur, R.H.; Pianka, E.R. On optimal use of a patchy environment. Am. Nat. 1966, 100, $603-609$. Available online: https://www.jstor.org/stable/2459298?seq=1 (accessed on 5 July 2020). [CrossRef]

41. Stephens, D.W.; Krebs, J.R. Foraging Theory; Princeton University Press: Princeton, NJ, USA, 1987; Volume 1, ISBN 9780691084428.

42. Gremillion, K.J. Seed processing and the origins of food production in eastern North America. Am. Antiq. 2004, 69, 215-233. Available online: https://www.jstor.org/stable/4128417?seq=1\#metadata_info_tab_contents (accessed on 10 June 2018). [CrossRef]

43. Gremillion, K.J.; Piperno, D.R. Human behavioral ecology, phenotypic (developmental) plasticity, and agricultural origins: Insights from the emerging evolutionary synthesis. Curr. Anthropol. 2009, 50, 615-619. Available online: https://www.journals.uchicago.edu/doi/abs/10.1086/605360 (accessed on 15 April 2020). [CrossRef] [PubMed]

44. Miller, D.S. From Colonization to Domestication: Population, Environment, and the Origins of Agriculture in Eastern North America; University of Utah Press: Salt Lake City, UT, USA, 2018; ISBN 1607816164.

45. Pearsall, D.M. Investigating the Transition to Agriculture. Curr. Anthropol. 2009, 50, 609-613. Available online: https://www.jstor.org/stable/10.1086/605406\#metadata_info_tab_contents (accessed on 15 April 2020). [CrossRef]

46. Winterhalder, B.; Kennett, D.H. Four neglected concepts with a role to play in explaining the origins of agriculture. Curr. Anthropol. 2009, 50, 645-648. Available online: https://www.jstor.org/stable/10.1086/ 605355?seq=1\#metadata_info_tab_contents (accessed on 15 April 2020). [CrossRef] [PubMed]

47. Jackson, M.C.; Britton, J.R. Stable isotope analyses indicate trophic niche overlap of invasive Pseudorasbora parva and sympatric cyprinid fishes. Ecol. Freshw. Fish 2013, 22, 654-657. Available online: https: //onlinelibrary.wiley.com/doi/pdf/10.1111/eff.12063 (accessed on 15 April 2020). [CrossRef]

48. Hamilton, S.; Johnston, R.F. Evolution in the House Sparrow; VI. variability and niche width. Auk 1978, 95, 313-323. Available online: https://academic.oup.com/auk/article-abstract/95/2/313/5208845?redirectedFrom= fulltext (accessed on 15 April 2020).

49. Soule, M.; Stewart, B.R. The "niche-variation" hypothesis: A test and alternatives. Am. Nat. 1970, 104, 85-97. Available online: https://www.jstor.org/stable/2459075?seq=1\#metadata_info_tab_contents (accessed on 15 April 2020). [CrossRef]

50. Werner, T.K.; Sherry, T.W. Behavioral feeding specialization in Pinaroloxias inornata, the "Darwin's finch" of Cocos Island, Costa Rica. Proc. Natl. Acad. Sci. USA 1987, 84, 5506-5510. Available online: https: //www.pnas.org/content/84/15/5506 (accessed on 15 April 2020). [CrossRef]

51. Van Valen, L. Morphological variation and width of ecological niche. Am. Nat. 1965, 99, 377-390. Available online: https://www.jstor.org/stable/2459179?seq=1\#metadata_info_tab_contents (accessed on 15 April 2020). [CrossRef]

52. Snyder, W.E.; Evans, E.W. Ecological effects of invasive arthropod generalist predators. Annu. Rev. Ecol. Evol. Syst. 2006, 37, 95-122. Available online: https://www.annualreviews.org/doi/full/10.1146/annurev.ecolsys.37. 091305.110107 (accessed on 15 April 2020). [CrossRef]

53. Olsson, K.; Stenroth, P.; Nyström, P.; Graneli, W. Invasions and niche width: Does niche width of an introduced crayfish differ from a native crayfish? Freshw. Biol. 2009, 54, 1731-1740. Available online: https://portal.research.lu.se/portal/en/publications/invasions-and-niche-width-does-niche-width-ofan-introduced-crayfish-differ-from-a-native-crayfish(e78fca3d-d88c-40fc-9628-292b33506e33).html (accessed on 15 April 2020). [CrossRef]

54. Porter, S.D.; Savignano, D.A. Invasion of polygyne fire ants decimates native ants and disrupts arthropod community. Ecology 1990, 71, 2095-2106. Available online: https://esajournals.onlinelibrary.wiley.com/doi/10. 2307/1938623 (accessed on 15 April 2020). [CrossRef]

55. Hutchinson, G.E. Concluding Remarks. Cold Spring Harb. Symp. Quant. Biol. 1957, $22,415-421$. Available online: http://symposium.cshlp.org/content/22/415 (accessed on 1 September 2020). [CrossRef]

56. Bolnick, D.I.; Ingram, T.; Stutz, W.E.; Snowberg, L.K.; Lau, O.L.; Paull, J.S. Ecological release from interspecific competition leads to decoupled changes in population and individual niche width. Proc. R. Soc. B Biol. Sci. 2010, 277, 1789-1797. [CrossRef] [PubMed] 
57. Svanbäck, R.; Bolnick, D.I. Intraspecific competition affects the strength of individual specialization: An optimal diet theory method. Evol. Ecol. Res. 2005, 7, 993-1012. [CrossRef]

58. Araújo, M.S.; Bolnick, D.I.; Layman, C.A. The ecological causes of individual specialisation. Ecol. Lett. 2011, 14, 948-958. [CrossRef] [PubMed]

59. Penk, M.; Irvine, K.; Donohue, I. Ecosystem-level effects of a globally-spreading invertebrate invader are not moderated by a functionally similar native. J. Anim. Ecol. 2015, 84, 1628-1636. [CrossRef]

60. Smith, B.D. A comparison of niche construction theory and diet breadth models as explanatory frameworks for the initial domestication of plants and animals. J. Archaeol. Res. 2015, 23, 215-262. Available online: https://link.springer.com/article/10.1007/s10814-015-9081-4 (accessed on 15 April 2020). [CrossRef]

61. Boserup, E. The Conditions of Agricultural Growth: The Economics of Agrarian Change under Population Pressure; Transaction Publishers: New Brunswick, NJ, USA, 2011; ISBN 9781138537187.

62. Zeanah, D.W. Foraging models, niche construction, and the Eastern Agricultural Complex. Am. Antiq. 2017, 82, 3-24. Available online: https://www.cambridge.org/core/journals/american-antiquity/article/foragingmodels-niche-construction-and-the-eastern-agricultural-complex/7481D608E03F7864C6C6FB5990F1B9F1 (accessed on 15 April 2020). [CrossRef]

63. David, N.; Kramer, C. Ethnoarchaeology in Action; Cambridge University Press: New York, NY, USA, 2001; ISBN 9780521667791.

64. Gifford-Gonzales, D. Ethnoarchaeology_Looking back, looking forward. SAA Archaeol. Rec. 2010, 10, 22-25. Available online: http://digital.ipcprintservices.com/publication/?i=30669\&article_id=308302\&view= articleBrowser (accessed on 15 April 2020).

65. Yu, P. Ethnoarchaeology as a strategy for building frames of reference for research problems. In Hunter Gatherer and Mid-Range Societies, Encyclopedia of Global Archaeology; Prentiss, A., Ed.; Springer Publishing: New York, NY, USA, 2014; ISBN 9781441904263.

66. Song, Y.C.; Xu, G.S. A Scheme of Vegetation Classification of Taiwan, China. Acta Bot. Sin. 2003, 45, 883-895. Available online: https://europepmc.org/article/cba/364797 (accessed on 15 April 2020).

67. Lee, C.Y.; Liew, P.M. Late Quaternary vegetation and climate changes inferred from a pollen record of Dongyuan Lake in southern Taiwan. Palaeogeogr. Palaeoclimatol. Palaeoecol. 2010, 287, 58-66. Available online: https:/www.sciencedirect.com/science/article/pii/S0031018210000167? casa_token=3oPH7oCmZY8AAAAA:sbce5Q82gnmOkAUpF9GWZFF-YE2S-XwRbanPffYAc6cEC9JDQgcq6xbiK9G6unkjBbAIXOnqg (accessed on 5 July 2020). [CrossRef]

68. Tsang, C.H.; Li, K.T. Archaeological Heritage in the Tainan Science Park of Taiwan; National Museum of Prehistory: Taitung City, Taiwan, 2018; ISBN 9789860474138.

69. Chen, C.T.A.; Ruo, R.; Paid, S.C.; Liu, C.T.; Wong, G.T.F. Exchange of water masses between the East China Sea and the Kuroshio off northeastern Taiwan. Cont. Shelf Res. 1995, 15, 19-39. Available online: https://www.sciencedirect.com/science/article/pii/0278434393E0001O (accessed on 22 April 2020). [CrossRef]

70. Lin, J.X.; Dai, L.P.; Yuan, W.; Min, L. Quaternary marine transgressions in eastern China. J. Palaeogeogr. 2012, 1, 105-125. Available online: https://www.sciencedirect.com/science/article/pii/S209538361530119X (accessed on 22 April 2020).

71. McCullough, D.R.; Takatsuki, S.; Kaji, K. (Eds.) Sika deer: Biology and Management of Native and Introduced Populations; Springer Science \& Business Media: Berlin, Germany, 2008.

72. Lien, C.M. Chang-pin Culture of Taiwan and Characteristics of Its Lithic Industry. In Emergence and Diversity of Modern Human Behavior in Paleolithic Asia; Kaifu, Y., Izuho, M., Goebel, T., Sato, H., Ono, A., Eds.; Texas A \& M Press: College Station, TX, USA, 2014; pp. 239-248, ISBN 9781623492762.

73. Sung, W.S. The archaeology of Taiwan. In Taiwan of China; Chen, C.L., Ed.; Zhongyang Wenwu Gongyingshe: Taipei, Taiwan, 1980; pp. 93-220. (In Chinese)

74. Sung, W.S. Changpinian: A Newly Discovered Pre-Ceramic Culture from the Agglomerate Caves on the East Coast of Taiwan; Newsletter of Ethnological Society of Taiwan: Taipei, Taiwan, 1969; Volume 9, pp. 1-9.

75. Tsang, C.H.; Chen, W.S.; Li, K.T. A Progress Report on First Year Results of the Ba Xian Dong Archaeological Survey Research Project; Academia Sinica: Taipei, Taiwan, 2009. (In Chinese)

76. Tsang, C.H.; Chen, W.S.; Li, K.T. (Eds.) Tai Dong Chang Bin Ba Xian Dong Yi Zhi Diao Cha Yan Jiu Ji Hua (Di Er Nian); Academia Sinica: Taipei, Taiwan, 2011. (In Chinese) 
77. Tsang, C.H. Lun Changbin Wenhua de Niandai yu Leiyuan. In Baxiandong Guodeng Yizhi Baohu yu Yanjiu Guoji Xueshu Yantaohui Luwenji; Wenhuabu Wenhua Zichanju, Taidongxian Zhengfu, Zhongyang Yanjiuyan, Lishi Yuyan yankuisuo Zhixing: Taipei, Taiwan, 2013; pp. 1-23. (In Chinese)

78. Kuo, S.C. New Frontiers in the Neolithic Archaeology of Taiwan (5600-1800 BP); Springer: New York, NY, USA, 2019; ISBN 9789813292628.

79. Chen, W.C. The Early Occupation of Taiwan. In The Handbook of East and Southeast Asian Archaeology; Habu, J., Lape, P.V., Olsen, J.W., Eds.; Springer: New York, NY, USA, 2017; pp. 277-291, ISBN 9781493965212.

80. Liu, Y.; Guo, S.; Lu, R. Taimin Diqu Kaogu Yihi Pucha Yanjiu Jihua (Diqiqi); Taipeixian, Jilongshi, Taipeishi, Neizhengbu Weituo, Zhongyang Yanjiuyan, Lishi Yuyan yankuisuo Zhixing: Taipei, Taiwan, 2004.

81. Liu, Y. 2011 Zhuminzhi Kaogupian. In Taiwan Quanzhi; Guoshiguan Taiwan Wenxianguan: Nantou, Taiwan, 2011; Volume 3.

82. Liu, Y.; Chen, J.; Zheng, H.; Li, J. Taizhongxian Kaogu Yizhi Pucha yu Yanjiu Jihua Yanjiu Baogao; Taizhongixian Wenhuaju Weituo, Zhongyan Yanjiuyuan Renwen Shehui Kexue Zongxin, Kaoguxue Yanjiu Zhuanti Zhongxin Zhixing: Taichung, Taiwan, 2007.

83. Liu, Y. Disanzhang: Shiqian Yizhi. In Taizhong Xianzhi (Juanyi) Tudizhi; Taizhongxian Zhengfu: Taichung, Taiwan, 1989; pp. 773-849.

84. Li, K.T. 1985 Duiyu Taiwan Kaogu Yanjiu de Ryogan Renshi; Taiwan Wenxian: Taipei, Taiwan, 1985; Volume 36, pp. 15-23.

85. Huang, S.; Chen, Y.; Yan, X. Kending Guojia Gongyuan Kaogu Minzhu Diaocha Baogao; Neizhengbu Yingjianshu Kending Guojia Gongyuan Guanlichu Weituo, Guoli Taiwan Daxue Renlei Xuexi Zhixing: Taipei, Taiwan, 1987.

86. Li, K.T.; Liu, Y.; Chang, C. Eluanbi Gongyuan Kaogu Diaocha Baogao; Jiaotongbu Guangguangju Kending Fenjing Tedingqu Guanlingchu Weituo, Guoli Taiwan Daxue Renlei Xuexi Zhixing: Taipei, Taiwan, 1983.

87. Huang, S.; Chen, Y. Donghe Diqu Yizhi Shijue di Shiqian Wenhua Chongjian; Xingzhengyuan Wenhua Jianshe Weiyuanhui Weituo, Guoli Taiwan Daxue Renlei Xuexi Zhixing: Taipei, Taiwan, 1990.

88. Binford, L.R.; Johnson, A.L. Program for Calculating Environmental and Hunter-Gatherer Frames of Reference (ENVCALC2.1). Updated Java Version. August 2014. Available online: http://ajohnson.sites.truman.edu/ data-and-program/ (accessed on 25 June 2018).

89. Lin, C.; Taiwan Forestry Research Institute, Taipei; Yu, P.; Boise State University, Boise, ID, USA. Personal communication, 2017.

90. Butal, A.; Tung, G.S.; Miaraw, P. The Ethnobotany of Amis in Eastern Formosa; Jen Teh Yen, Council of Agriculture Executive Yuan: Taipei, Taiwan, 2009; ISBN 9789860223156.

91. Lu, T.H.; Ke, Y.N.; Lin, S.F.; Lu, S.Y. Plants Used by Paiwan in Taiwan; Report prepared for Taiwan Forestry Bureau, Council of Agriculture, Executive Yuan: Taipei, Taiwan, 2011.

92. Simpson, E.H. The Measurement of Diversity. Nature 1949, 163, 688. Available online: https://www.nature. com/articles/163688a0 (accessed on 15 April 2020). [CrossRef]

93. Chu, C.Y. Report on the restoration, excavation, construction, and supervision of the Talungtung Site (Dalongdong Yizhi Qiangjiu Fajue Ji Shigong Jiankan Jihuau Chengguo Baogao); Tree Valley Foundation, Taipei City Government Department of Cultural Affairs: Taipei, Taiwan, 2012. (In Chinese)

94. Huang, S.C. Report on Archaeological Investigation at Pa-chia Village, Kui-jun Township; Bulletin of the Department of Archaeology and Anthropology: Tainan, Taiwan, 1974; pp. 62-68. (In Chinese)

95. Tsang, C.H. Archaeology of the Penghu Islands; Academia Sinica: Taipei, Taiwan, 1992; ISBN 9789576710483. (In Chinese)

96. National Museum of Natural Science. Report on the Salvage Excavation Project at the Construction Site at the "Anho Road Site"; Report commissioned by Ching He Construction Co., Ltd.; National Museum of Natural Science: Taichung City, Taiwan, 2016. (In Chinese)

97. Tsang, C.H. (Ed.) Final Report on the Tainan Science Park Archaeological Rescue and Monitoring Project; Taiwan National Museum of Prehistory: Taitung City, Taiwan, 2006. (In Chinese)

98. Tsang, C.H. Final Report on the Archaeological Project of Restoring Areas of the Taoyeh Site Excluded from the Preservation Area, Tainan Science Park; Report prepared for the Southern Taiwan Science Bureau; Institute of History and Philology, Academia Sinica: Taipei, Taiwan, 2004. (In Chinese) 
99. Chen, S.Q.; Yu, P. Early 'Neolithics' of China: Variation and Evolutionary Implications. J. Anthropol. Res. 2017, 73, 149-180. Available online: https://www.journals.uchicago.edu/doi/abs/10.1086/692104?af=R (accessed on 22 April 2020). [CrossRef]

100. Liu, L.; Field, J.; Fullagar, R.; Zhao, C.; Chen, X.; Yu, J. A functional analysis of grinding stones from an early Holocene site at Donghulin, North China. J. Archaeol. Sci. 2010, 37, 2630-2639. Available online: https://www.sciencedirect.com/science/article/pii/S0305440310001858 (accessed on 22 April 2020). [CrossRef]

101. Sagart, L.; Hsu, T.F.; Tsai, Y.C.; Wu, C.C.; Huang, L.T.; Chen, Y.C.; Chen, Y.F.; Tseng, Y.C.; Lin, H.Y.; Hsing, Y.I.C. A northern Chinese origin of Austronesian agriculture: New evidence on traditional Formosan cereals. Rice 2018, 11, 57-73. Available online: https://thericejournal.springeropen.com/articles/10.1186/s12284-018-0247-9 (accessed on 15 April 2020). [CrossRef]

102. Jiao, T.L. Toward an alternative perspective on the foraging and low-level food production on the coast of China. Quat. Int. 2016, 419, 54-61. Available online: https://www.sciencedirect.com/science/article/pii/ S1040618215006606 (accessed on 15 April 2020). [CrossRef]

103. Zhang, C.; Hung, H.C. Later hunter-gatherers in southern China, 18,000-3000 BC. Antiquity 2012, 86, 11-29. Available online: https://www.cambridge.org/core/journals/antiquity/article/later-huntergatherers-insouthern-china-18-0003000-bc/AE598987DF32F318EB18B4CA16B814E0 (accessed on 15 April 2020).

(C) 2020 by the author. Licensee MDPI, Basel, Switzerland. This article is an open access article distributed under the terms and conditions of the Creative Commons Attribution (CC BY) license (http://creativecommons.org/licenses/by/4.0/). 